\title{
MANEJO Y CULTIVO DE PLANTAS EN SIERRAS HÚMEDAS DEL NE DE BRASIL CA. 670-530 BP: EVIDENCIAS PALINOLÓGICAS DEL YACIMIENTO EVARISTO I
}

Se presentan las primeras huellas culturales de antiguas poblaciones alfareras de la Serra de Baturité. El espectro polínico de los sedimentos evidencia un mosaico de vegetación húmeda montañosa, xerófitas, anuales nitrófilas, higrófitas y plantas de turberas. El polen útil recuperado de las cerámicas, como la yuca (tipo Manihot), el camote (tipo Ipomoea), el algodón (tipo Gossypium), las palmeras y fructíferas (tipo Arecaceae, Astronium y cf. Anacardium), juntamente con los microhongos patógenos del maíz, del algodón y de algunos tubérculos (tipo Curvularia, tipo Alternaria, tipo Puccinia y cf. Ustilago maydis) indican actividades agrícolas y de subsistencia. Los hongos coprófilos de humanos y otros animales (tipo Cercophora, Gelasinospora y tipo Sordariaceae) reflejan el tiempo de permanencia de esos grupos en la zona arqueológica. El hongo Gelasinospora también muestra el uso del fuego como combustible para las prácticas agrícolas y caza. Esos datos demuestran el uso de la cerámica en contextos funerario y doméstico.

Palabras clave: arqueopalinología, paleoetnobotánica, paleoecología, cerámica, subsistencia.

Crop Management Practices in the Humid Hills from Northeastern Brazil between 670-530 Yrs BP: Palynological Evidences from Archaeological Site Evaristo I

The first cultural traces of ancient pottery towns in the Serra de Baturite are presented. The pollen spectrum of sediments reveals a mosaic of moist mountainous vegetation, xerophytes, annual nitrophilous, hygrophilous and bog plants. Useful pollen recovered from ceramic, such as cassava (Manihot type), sweet potatoes (Ipomoea type), cotton (Gossypium type), palm trees and fruitful (Arecaceae, cf. Astronium and Anacardium type), together with pathogenic microfungi corn, cotton and some tubers (Curvularia type, Alternaria, Puccinia type and cf. Ustilago maydis) indicate agricultural and livelihood activities. The coprophilous fungi of humans and other animals (Cercophora type Gelasinospora type and Sordariaceae) reflect the time spent by these groups in the archaeological area. The Gelasinospora fungus also shows the use of fire as fuel for agricultural practices and hunting. These data demonstrate the use of ceramics in funerary and domestic contexts.

Key words: archaeopalynology, paleoethnobotany, paleoecology, pottery, subsistence.

Los estudios arqueopalinológicos ayudan a la comprensión de los aspectos culturales de las poblaciones humanas en el pasado, especialmente a través de los cambios en la vegetación natural causados por la acción antrópica (Bryant y Hall 1993; Carrión et al. 2009). Los espectros polínicos recuperados de yacimientos arqueológicos pueden ser a veces inadecuados para estudios paleoclimáticos debido a problemas tafonómicos que afectan la preservación polínica (Carrión et al. 2000), sin embargo nos ofrecen a menudo información muy valiosa sobre las actividades humanas y las culturas prehistóricas (Dimbleby 1985; Holloway y Bryant 1986). El polen de plantas consumidas por antiguas poblaciones adherido a las vasijas cerámicas, piedras de moler u otros artefactos 
Aline Gonçalves de Freitas, José Sebastián Carrión García, Santiago Fernández Jiménez, Igor Pedroza, Caroline Fernandes Caromano, Leandro Mathews Cascón, Gina Faraco Bianchini, Sergio Francisco Serafim Monteiro da Silva, Neuvania Curty Ghetti, Claudia Alves de Oliveira

reflejan su uso y función, y constituye evidencia directa del cultivo, procesamiento y almacenamiento de vegetales. Esos datos son bastante significativos en zonas con mala preservación (Holloway y Bryant 1986). El polen también puede proveer indicios paleoeconómicos sobre la paleodieta, como sucede con los coprolitos humanos y de otros animales (Carrión et al. 2005). Los análisis polínicos en cuevas con sedimentos arqueológicos han demostrado que las altas concentraciones polínicas en muestras del interior de las cavidades pueden representar la vegetación del entorno, en algunos casos, superando a los obtenidos en las muestras del exterior, como es el caso de la cueva del Ardacho (Murcia, España) (Navarro et al. 2000) y Cova Beneito (Alicante, España) (Carrión y Munuera 1997). Por otro lado, esos análisis en yacimientos al aire libre documentan impactos de la agricultura sobre el medio, procesos de degradación ambiental, pérdida de recursos forestales, así como antropización como factor principal en la configuración del paisaje (Fuentes et al. 2005).

Basándose en los aspectos naturales y culturales, este trabajo tiene por objetivos: (1) caracterizar la vegetación del entorno, en la época del entierro de las vasijas cerámicas; (2) identificar la dieta y uso de plantas por grupos alfareros prehistóricos; (3) indicar la posible utilización de la cerámica producida por ellos.

\section{LOS GRUPOS ALFAREROS EN EL SEMIÁRIDO BRASILEÑO}

Las ocupaciones más antiguas en el NE de Brasil relacionadas a la producción de cerámica datan de 8960ะ70 BP (Yacimiento del Meio, Serra da Capivara, Piauí: Guidon y Pessis 1993), seguida de otros yacimientos como: Toca da Extrema $2(4730 \pm 110$ BP e $3100 \pm 50$ BP), Justino I

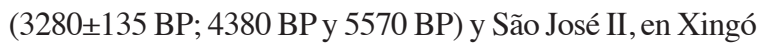
(Sergipe), abrigo Toca do Pinga do Boi (Piauí) (3320 \pm 60 BP y $3010 \pm 60$ BP) y Alcobaça (Pernambuco) $(4733 \pm 29$ BP y 4243 \pm 26 BP) (Maranca 1991; Oliveira 2001; 2003).

La agricultura en el NE brasileño puede tener su origen $c a$. $3000 \mathrm{BP}$, con un escaso número de cazadoresrecolectores que la practicaban en pequeñas zonas de subsistencia (Martin 1998; Oliveira 2003). Llobera (1979) define por agricultura de subsistencia, la cultura de semillas, raíces y tubérculos donde se utilizaron herramientas de producción (i.e., pau-de-cavar o enxada), desbroce y quema de leño, que conducen al agotamiento del suelo en corto plazo y a la búsqueda otros recursos alimentarios, como la caza y la recolección. Alrededor de $3300 \mathrm{BP}$, se registra una cerámica muy sencilla, con forma alisada o raspada y decoración globular u ovoide. En torno a $2000 \mathrm{BP}$ tiene lugar un aumento poblacional que introdujo nuevos grupos alfareros dotados de una tecnología diversificada, con decoración variada (corrugada, ungulada, escovada, incisa y pintada) y diferentes formas y tamaños, desde pequeños cuencos de cocina a grandes urnas funerarias (Oliveira 2003; Etchevarne 2012). En áreas interiores se documentó la ocupación de grupos humanos relacionados con la dispersión de la cerámica Tupiguarani, ca. $1100 \mathrm{BP}$ hasta el contacto europeo (s. XVI) (Etchevarne 2012). Albuquerque y Lucena (1991) asociaron estas ocupaciones al cambio climático ocurrido durante el Holoceno, debido a la expansión y retracción de la vegetación en áreas puntuales. Los Brejos de altitude (Ab'Sáber 1994) fueron importantes zonas de concentración de poblaciones humanas del pasado, dada sus condiciones físicas y ecológicas para el desarrollo de actividades agrícolas y supervivencia de esos grupos (Martin 1998). Según Albuquerque y Lucena (1991), esas poblaciones estarían relacionadas principalmente al cultivo de yuca, que fue el vegetal más consumido en la América tropical durante la Prehistoria, incluyendo sus variedades más importantes: yuca amarga (Manihot esculenta), yuca brava (Manihot utilissima) y yuca dulce (Manihot aipi). La tecnología exigida en la preparación, consumo y almacenamiento de la yuca y sus subproductos incluye una gama de artefactos cerámicos (vasijas y asadores), líticos (ralladores, lascas, hachas o ejes pulidos o lascados) y manufacturados de plantas (cestos de algodón y de paja de palmera y gramíneas) (Pearsall 1992).

En la prehistoria del semiárido brasileño, los datos del cultivo de plantas todavía son incipientes. La influencia antrópica en el paisaje fue registrada ca. $4500 \mathrm{BP}$ simultáneamente en el Yacimiento Alcobaça (Pernambuco) $(4733 \pm 29$ BP y $4243 \pm 26$ BP) por los vestigios de maíz, frutos de palmeras (babaçu, ouricuri, coquinho) y umbú (Oliveira 2001), y en el Vale do Catimbau (Pernambuco), por la presencia de frutales como el babaçu (Orbignya), el cajá o la serigüela (Spondias sp.) (Nascimento et al. 2009). En el mismo intervalo, en tierras bajas de Colombia, los macrorrestos vegetales y granos de polen indican el consumo de frutos de palmera (Orbygnia sp., Astrocaryum standleyanum, Bactris sp. y Geonoma deversa), calabaza (Cucurbita maxima), maíz (Zea mays), camote (Ipomoea sp.). Estas plantas pueden haber 
sido cultivadas como estrategia para la producción de alimentos y establecimiento local de grupos alfareros (Romero 1995 apud Archilla 2009). En el Yacimiento funerario Toca do Gongo I (2090 \pm 110 BP) (Piauí) fueron encontrados artefactos cerámicos y líticos, restos de fogones, semillas de avellanas, frijol, calabazas enteras o fragmentadas y objetos hechos de fibra de caroá (Neoglaziovia variegata), asociados a los esqueletos de nueve tumbas (Maranca 1991). En esa zona, además, se ha detectado la presencia de mazorcas de maíz en lechos sedimentarios entre 1600-1200 BP (Laroche 1975 apud Martin 1998). Los indicios sobre la ocupación de los grupos alfareros en las sierras húmedas de la Provincia de Ceará todavía son escasos, teniendo como uno de sus primeros registros el yacimiento Evaristo I (fig. 1). Los hallazgos cerámicos y líticos aparecen asociados a un contexto funerario y doméstico bajo producción intensiva de los mismos (Oliveira y Pedroza 2014). Los vestigios arqueopalinológicos registrados hasta ahora son las primeras informaciones sobre plantas probablemente utilizadas en el consumo, dieta y contexto funerario de poblaciones alfareras (Pedroza et al. 2014). Estas necesidades dan soporte a la reconstrucción del modo de vida y las formas de obtener recursos vegetales de las comunidades prehistóricas y sus relaciones etnobotánicas (Martin 1998). Según Bianchini et al. (2011) los macro y microrrestos botánicos preservados en sitios arqueológicos también indican la presencia de material cultural de poblaciones prehistóricas al tratarse de elementos derivados de la modificación humana.

\section{PALEOAMBIENTE Y PALEOPAISAJE HOLOCÉNO}

Los indicadores paleoambientales, paleoclimáticos y de paleopaisaje en el semiárido del NE brasileño en el contexto de las ocupaciones humanas prehistóricas, todavía son escasos y puntuales, debido a las dificultades metodológicas y discontinuidades sedimentarias de los yacimientos (Chaves 2002; Nascimento et al. 2009; Mützenberg 2010; Pessenda et al. 2010). Los estudios paleoclimáticos de la transición Pleistoceno-Holoceno (entre 12,000-11,000 BP) indican un aumento de la humedad, expansión forestal y microclimas más fríos (De Oliveira et al. 1999; Behling et al. 2000). Entre 90006000 BP, hubo un clima más cálido y húmedo, con áreas abiertas y expansión de vegetación xerofítica (Cerrado y Caatinga), y clímax de los bosques-galería sobre 4240
BP (Ledru et al. 2006). En torno a 3000 BP, el semiárido presenta un clima más seco, semejante al actual (Cruz Junior et al. 2009), con intensificación de la desertificación y sustitución de vegetación higrofítica por xerofítica en diversas áreas, sobre todo a partir de 1300 BP, coincidiendo en este intervalo con los periodos de ocupación antrópica. Mientras tanto, la presencia actual de islas o refugios de vegetación húmeda en puntos del semiárido nororiental puede ser justificada por la expansión de las plantas atlánticas y amazónicas, indicador de microclimas más húmedos durante el Holoceno (Ab’Sáber 1994; Pessenda et al. 2010).

En este contexto, sin embargo, los análisis polínicos de los yacimientos arqueológicos apuntan condiciones climáticas favorables para la ocupación humana, así como la presencia de agricultura de subsistencia durante el Holoceno (Chaves 2002; Nascimento et al. 2009). Los coprolitos de yacimientos de la Serra da Capivara (Piauí) indican refugios forestales (Combretaceae, Acacia y Mimosa) y paleodietas en torno a 8800 BP (Chaves 2002). El registro polínico y las dataciones radiocarbónicas del Vale do Catimbau (Pernambuco) reflejan una fase más seca entre 8410-5970 BP y una fase más húmeda entre 59701700 BP indicada por el polen de arecáceas (Orbignya), pteridófitas y algas dulceacuícolas. A partir de 1700 BP, se establecen las condiciones climáticas actuales (Nascimento et al. 2009).

\section{EL CONTEXTO ETNOHISTÓRICO}

Los datos etnohistóricos de la actual Provincia de Ceará presentan un escenario complejo por el registro de migraciones de poblaciones indígenas y europeas desde el s. XVII, marcada por las primeras incursiones de los europeos en tierras cearenses sobre el año de 1603, y por la segregación de los grupos indígenas que vivían en la costa, pertenecientes a dos grandes etnias: los Tupi, o lengua general y los Tapuia, o no Tupi (Pompeu Sobrinho 1955; Studart Filho 1962). A la familia lingüística de los Tapuia pertenecen los grupos indígenas Canindé, Paiacú e Jenipapo e Quixelôs. Estos grupos están relacionados con la historia administrativa de la zona de Baturité, fundada en 1764 (Studart Filho 1962). Los indígenas Jenipapo y Canindé son grupos del interior de la Provincia, que vivieron en constante circulación, habitando zonas cercanas a los ríos Choró, Quixeramobim y Banabuiú, llegando a la Serra de Baturité por esos flujos migratorios (Studart Filho 1962). 
Aline Gonçalves de Freitas, José Sebastián Carrión García, Santiago Fernández Jiménez, Igor Pedroza, Caroline Fernandes Caromano, Leandro Mathews Cascón, Gina Faraco Bianchini, Sergio Francisco Serafim Monteiro da Silva, Neuvania Curty Ghetti, Claudia Alves de Oliveira
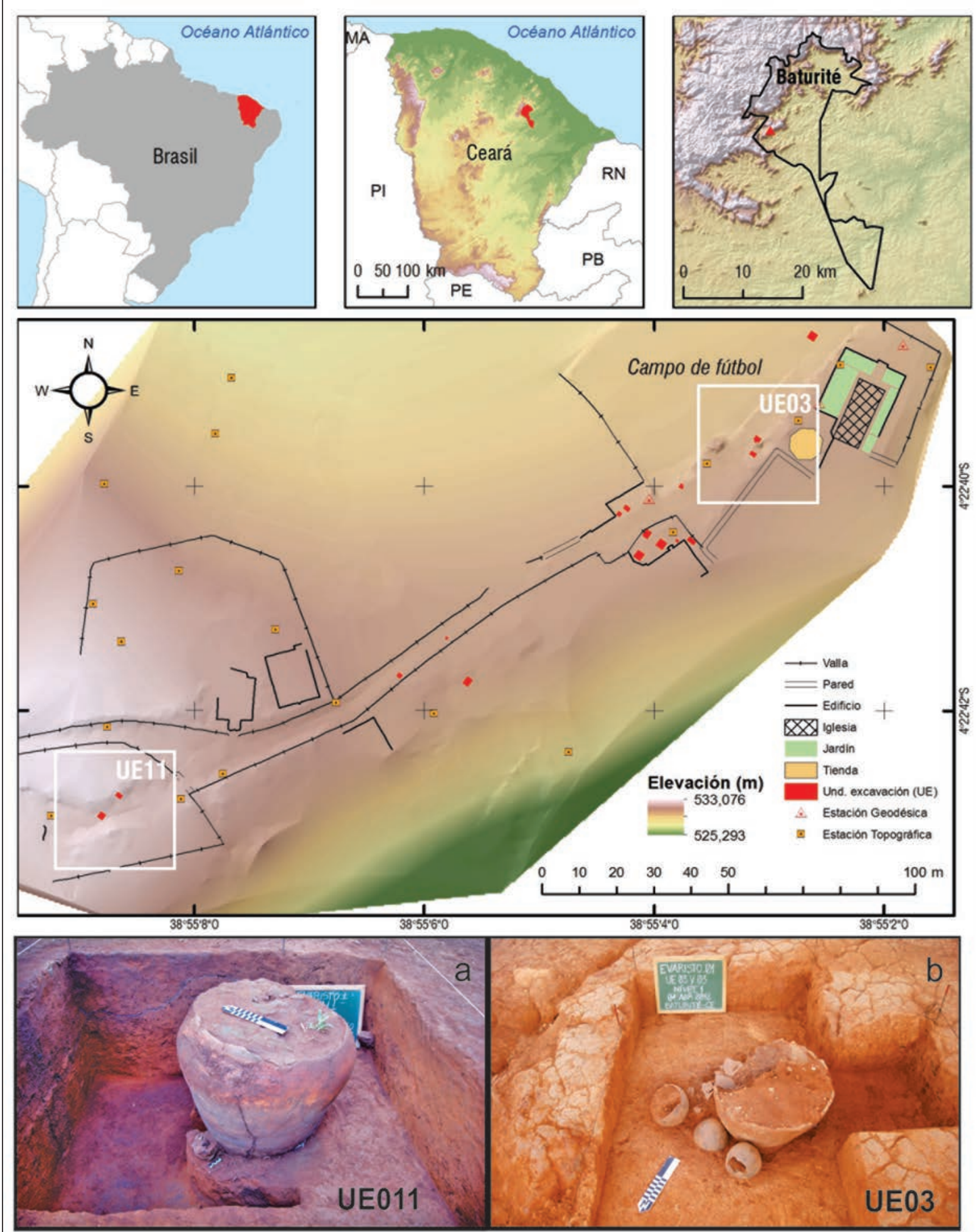

Fig. 1. Localización del yacimiento Evaristo I y de las unidades excavadas, objeto de análisis en este trabajo. 
El nomadismo implicaría guerras constantes por vivir en tierras sujetas a la sequía; condiciones que los llevaron a moverse en busca de agua e impidieron acarrear sus utensilios como morteros y ollas, difíciles de transportar.

\section{MATERIAL Y MÉTODOS. EL YACIMIENTO EVA- RISTO I}

\section{LOCALIZACIÓN Y CONTEXTO FITOGEOGRÁFICO}

El yacimiento Evaristo I se localiza en la provincia geomorfológica del Maciço do Baturité (600-1200 m), ubicado en la Provincia de Ceará, NE de Brasil (fig. 1). El clima es tropical cálido húmedo y subcálido húmedo, con temperaturas medias de $25{ }^{\circ} \mathrm{C}$ y precipitaciones de 20 $25,000 \mathrm{~mm} / \mathrm{año}$. La zona de Convergencia Intertropical (ZCIT) genera veranos y otoños húmedos y los vientos de NE-E del Anticiclón subtrópical del Atlántico Sur provocan inviernos y primaveras secas (Nimer 1989). Los ríos que abastecen a la región pertenecen a dos cuencas: occidental, por el Río Curu y oriental, por el Río Aracoiaba, de la Subcuenca del Río Choró (SRH 2003 apud Nunes y Portela 2011). Los suelos son una asociación del tipo Podzólico PV1 (Rojo-Amarillo y Rojo-Amarillo Eutrófico A) con textura arcillosa y bastante alterado por el microclima regional (SEMACE 1992).

De acuerdo con Veloso et al. (1991), la vegetación Atlántica nordestina está subdividida en Floresta Semicaducifolia Montana y Floresta Húmeda Montana (Brejos de altitude) en asociación con la Caatinga, ocurrente en la Depressão Sertaneja. La presencia actual de un mosaico de especies atlánticas, como el murici (Byrsonima sericea), el ipê-amarelo (Tabebuia serratifolia) entre otros y especies amazónicas, como la favinha (Stryphnodendron purpureum), la paraíba (Simarouba amara) y la copaíba (Copaifera langsdorfii) sustentan la hipótesis de una conexión florística entre esas provincias fitoflorísticas en el pasado (Ab'Sáber 1994). Las montañas bajas (hasta 650 m.s.n.m.), como la zona estudiada, presenta condiciones de menor humedad en la vertiente occidental (sotavento), asumiendo climas de húmedo a seco y vegetación arbustivo-arbórea adaptada a la xerofilia, por ejemplo el angico (Anadenanthera colubrina), marmeleiro-branco (Croton argyrophylloides), tapiá (Crataeva tapia) y aroeira (Myracrodruon urundeuva) (Nunes y Portela 2011). La región posee gran riqueza y diversidad de especies de fauna y flora, convirtiéndose en Área de Protección Ambiental (APA da Serra de Baturité) en 1990 (SEMACE 1992).

\section{CONTEXTO ARQUEOLÓGICO: EXCAVACIÓN, MA- TERIALES Y DATACIONES}

Las intervenciones arqueológicas comenzaron en 2012 y comprendieron diecinueve puntos del yacimiento, dieciocho unidades de excavación (UEs) y una trinchera ( $2 \times 2 \mathrm{~m}$, excavada en forma de ajedrez) (fig. 1). Fueron recuperadas dieciocho vasijas cerámicas que tenían formas y tamaño diversos (10-80 $\mathrm{cm}$ de ancho, $10-90 \mathrm{~cm}$ de altura y $<0,5 \mathrm{y}>3,5 \mathrm{~cm}$ de grosor de las paredes). Las más grandes poseen forma ovalada, tendiendo a piriforme y las menores, globulares. Además de esos recipientes, fueron recuperados otros fragmentos cerámicos como borde, bajo, base y apliques, husos de hilar y pipas (fig. 2) y artefactos líticos, como lascas, hachas pulidas y adornos en cuarcita, sílex, granito y micaesquisto. La presencia de 82 piezas de hachas pulidas (fig. 3) está asociada al uso intensivo del suelo y trabajos con la madera, relacionándose con probables prácticas agrícolas y manejo de vegetales (Prous 1992).

En el contexto de las unidades arqueológicas estudiadas, los recipientes asumían caráter funerario y doméstico. La vasija grande de la UE02 corresponde a una urna funeraria, visto que contenía huesos y dientes humanos en un mal estado de conservación. Se trata de un individuo adulto,

\begin{tabular}{|c|c|c|c|}
\hline Vestigios cerámicos & Probable función & $\mathbf{N}^{0}$ & $\%$ \\
\hline fragmentos cerámicos & relacionados al uso doméstico y funerario & 4159 & 99,38 \\
\hline vasijas enteras & $\begin{array}{l}\text { cocción, almacenamiento de alimentos (contexto doméstico); inhumaciones individuales y rituales } \\
\text { (contexto funerario) }\end{array}$ & 15 & 0,36 \\
\hline husos de hilar & hacer redes de pesca y textiles (contexto doméstico) & 9 & 0,22 \\
\hline pipas partidas & pipa para fumar (contexto doméstico) y/o adorno u ofrenda (contex to funerario) & 2 & 0,05 \\
\hline Total & & 4185 & 100 \\
\hline
\end{tabular}

Fig. 2. Artefactos cerámicos arqueológicos recuperados del yacimiento Evaristo I. 


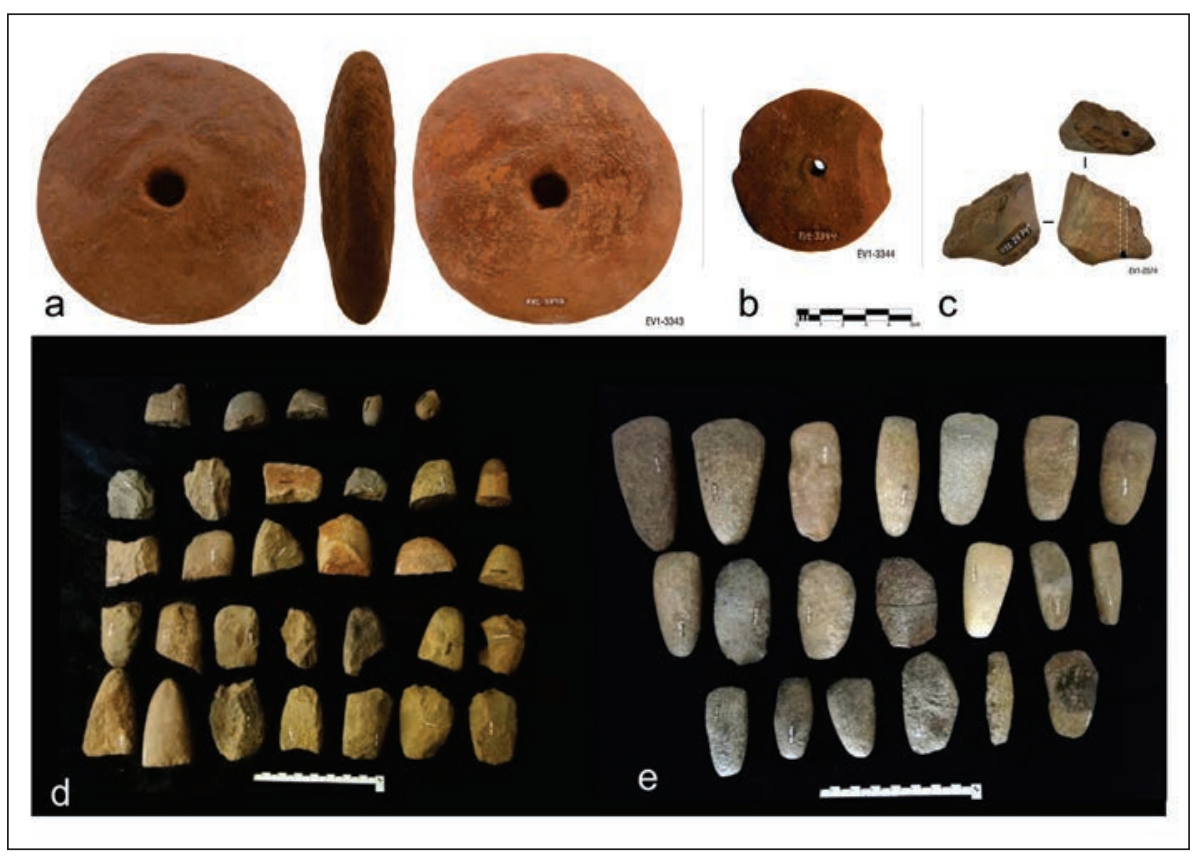

Fig. 3. Otros materiales arqueológicos recuperados: (a-b) Husos de hilar. (c) Fragmentos de pipa. Escala: $5 \mathrm{~cm}$. (d) Fragmentos de hachas. (e) Hachas de piedra pulida. Escala: 10 $\mathrm{cm}$.

con los huesos desarticulados, la mandíbula boca abajo y un hueso largo colocado lateralmente, que indican una posición sentada, con los miembros flexionados. Los dientes recuperados presentan desgastes de naturaleza fisiológica, asociados al proceso de mascar alimentos abrasivos como raíces, cortezas, pieles, huesos, semillas y alimentos cocidos en matrices de suelo o cenizas calientes. También se comprueba el desgaste dental por el uso de los dientes como herramienta para manejar o preparar fibras vegetales y cuero (Silva et al. 2014). En este trabajo nos centraremos en los recipientes de las unidades arqueológicas UE03 e UE011. La UE03 presentó una vasija fragmentada e incompleta de grandes proporciones (muestra EV-04238), con cenizas y cinco pequeñas vasijas globulares alrededor, siendo analizada una de ellas (muestra EV-2157) (fig. 1). La unidad UE011 (muestra EV-04233) (fig. 1) presentó una vasija íntegra de grandes proporciones, piriforme que aparece junto a una vasija de pequeñas proporciones, con bordes ondulados y apliques con probable uso de suspensión, aunque no ha sido analizada en este trabajo. En esta unidad no fueron identificados hallazgos funerarios.

Las dataciones absolutas por radiocarbono $\left({ }^{14} \mathrm{C}\right)$ AMS (Accelerator mass spectrometry) sobre fragmentos de carbón y por termoluminiscencia (TL) en las cerámicas (fig. 4) sugieren que la ocupación alfarera en el Yacimiento ocurrió entre 653-555 cal BP (1395-1297 cal AD)

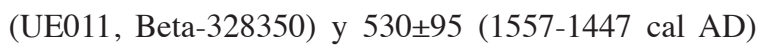
(UE03, Lab Cod-3622) (Oliveira y Pedroza 2014) (fig. 4).
La datación ${ }^{14} \mathrm{C}$ AMS fue realizada en el Laboratório Beta Analytic (EUA). Las edades convencionales fueron calibradas en el Programa Calib Rev 7.0.2 (Stuiver y Reimer 1993), usando de la curva de calibración SHCal13 (Hogg et al. 2013) tanto para las edades AD (Anno Domini) cuanto para las edades BP (Before Present), ambas con intervalo de confianza (i.c.) de $100 \%$. La datación por Termoluminiscencia (TL) fue realizada en el Laboratório Datação (Brasil). $\mathrm{El}{ }^{14} \mathrm{C}$ indica la fecha de la última quema de la madera. La TL muestra la última quema (por encima de $450{ }^{\circ} \mathrm{C}$ ) a la cual la cerámica fue sometida.

\section{ANÁLISIS POLÍNICOS}

\section{MUESTREO Y TRATAMIENTO QUÍMICO}

El muestreo arqueopalinológico fue puntual, con la selección de muestras en contexto cultural (i.e., suelos, artefactos y otros materiales) (Burjachs et al. 2000). Se tomaron cinco muestras: (1) fragmento interno (masa) de la vasija cerámica grande; (2) fragmento interno (masa) de la vasija cerámica pequeña globular; (3) sedimento interno de la vasija de la unidad UE03; (4) fragmento interno (masa) de la vasija cerámica grande piriforme; (5) sedimento interno de la vasija de la unidad UE011 (fig. 1). Fueron procesados ca.3-5 g de fragmentos cerámicos y ca. 30-50 g de sedimentos. Las cerámicas 


\begin{tabular}{|c|c|c|c|c|c|c|c|c|}
\hline Muestras & $\begin{array}{c}\text { Unidades } \\
\text { arqueológicas }\end{array}$ & $\mathbf{N}^{0}$ Lab & Referencia material & Método & Datación BP & Cal BP $2 \sigma$ & Cal $\Lambda D 2 \sigma$ & $\delta^{13} \mathrm{C}(\%)$ \\
\hline EV-04238-B & UL03-S & - & - & - & - & - & - & - \\
\hline EV-04233-B & UE011-S & - & - & - & - & - & - & - \\
\hline EV-02157 & UE03-c & - & - & - & - & - & - & - \\
\hline EV-04238 & UEO3-C & Lab-3622 & Fragmento cerámico & TL & $530 \pm 95$ & - & $1557-1447$ & - \\
\hline EV-04233 & UE011-C & Beta-328350 & Fragmento de carbón & $14 \mathrm{C}$ AMS & $670 \pm 30$ & $653-555$ & $1395-1297$ & 25.1 \\
\hline
\end{tabular}

Fig. 4. Dataciones absolutas ${ }^{14} \mathrm{C}$ y TL. ${ }^{*} \mathrm{C}=$ vasija cerámica grande; c=vasija cerámica pequeña; $\mathrm{S}=$ sedimentos internos a las vasijas (muestrascontrol).

fueron lavadas con agua destilada y escoba estéril para quitar las posibles concreciones adheridas en el post-deposicional (Holloway y Bryant 1986). El método de extracción de los palinomorfos consistió en el tratamiento con ácidos para la disolución de los carbonatos y silicatos ( $\mathrm{HCl}$ a $37 \%$ y $10 \%$ y $\mathrm{HF}$ a $40 \%$ ) y líquido denso (bromoformo; $\mathrm{D}=2.8$ ) para la concentración de los microrrestos orgánicos (Mendonça Filho et al. 2002). Visto que en las cerámicas se concentran naturalmente menos palinomorfos, a ninguna muestra se le aplicó agentes oxidantes, como el KOH ni acetolisis.

\section{IDENTIFICACIÓN Y RECUENTO POLÍNICO}

La identificación y el recuento polínico se realizaron en microscopio de luz transmitida Nikon Eclipse E-100. Los recuentos polínicos de las cerámicas se basaron en datos cualitativos, considerando su carácter etnobiológico (Holloway y Bryant 1986) (figs. 5-6). Los recuentos polínicos de los sedimentos obedecieron al mínimo cuantitativo fiable para análisis arqueopalinológicos, entre 150-200 pólenes o considerándose la presencia de al menos 20 taxones polínicos (Dimbleby 1985). La suma polínica incluye todos los palinomorfos terrestres (granos de polen, esporas de pteridófitos, microalgas dulciacuícolas y microhongos) (figs. 5; 7-8). Esos datos fueron tratados en Excel 2010, sistema Windows 8 para su representación gráfica.

La identificación y descripciones polínicas se fundamentan en los criterios morfológicos descriptivos de unidad de dispersión polínica, tamaño, polaridad, simetría, forma, posición de las aperturas y ornamentación de la exina. Por otro lado, los pteridófitos fueron descritos según el tipo de cicatriz, tamaño, forma, ornamentación del exosporio (Punt et al. 2007). Para tales fueron consultados atlas polínicos y otras publicaciones (Salgado-Labouriau 1973; Roubik y Moreno 1991; Bush y Weng 2007; Freitas y Carvalho 2012) (figs. 9-15). El tipo polínico se caracteriza por el establecimiento de proximidad del material analizado y determinado grupo taxonómico (Salgado-Labouriau 1973). Holloway y Bryant (1986) muestran la dificultad en la identificación del polen de plantas cultivadas, sobre todo cuando se analizan suelos de campos de cultivo modernos. Sin embargo, la identificación del polen económico (tipo Manihot, tipo Ipomoea y otros) en vasijas cerámicas suele indicar su uso y función, probablemente relacionada a prácticas agrícolas. Para tales inferencias, se buscó comparar los caracteres diagnósticos-clave entre los tipos polínicos de especies naturales y cultivadas (Saba 2007; Jayeola y Oladunjoye 2012; Jones y McCurry 2012; Vieira et al. 2012). Las identificaciones y datos ecológicos de las microalgas y microhongos fueron basadas en las publicaciones de Gelorini et al. (2011), Van Geel et al. (2011) y Freitas et al. (2015) (figs. 16-18). Las microfotografías fueron realizadas a través del software Zeiss Axio Vision en microscopio Zeiss Axioplan, con magnificaciones de 400x y 1000x. El análisis de correspondencia (CA) (fig. 19), hecho con el programa PAST 2.04 (Hammer et al. 2001) está basado en los datos polínicos cualitativos (presencia/ ausencia) para la observación de la distribución de los palinomorfos en las unidades arqueológicas con el fin de distinguir las zonas de actividad humana.

\section{RESULTADOS Y DISCUSIÓN}

\section{PRESERVACIÓN POLÍNICA}

El estado de preservación de los palinomorfos en general fue satisfactorio, más en los sedimentos que en los artefactos cerámicos, caracterizando una preservación diferencial, común en contexto arqueológico (Dimbleby 1985). Clark (1989) apud Bryant y Hall (1993) citan que, una gran fracción referente al polen de plantas como la calabaza, el maíz, el algodón y otras plantas de interés económico pueden tener difícil recuperación en sedimentos arqueológicos. Además, el número de granos de polen 
Aline Gonçalves de Freitas, José Sebastián Carrión García, Santiago Fernández Jiménez, Igor Pedroza, Caroline Fernandes Caromano, Leandro Mathews Cascón, Gina Faraco Bianchin, Sergio Francisco Serafim Monteiro da Silva, Neuvania Curty Ghetti, Claudia Alves de Oliveira

\begin{tabular}{|c|c|c|c|c|c|c|}
\hline \multirow{23}{*}{ 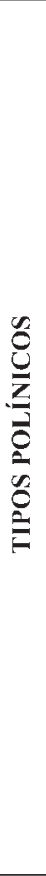 } & Muestras arqueopalinológicas & UE011-C & UE03-C & UE03-c & UE011-S & UE03-S \\
\hline & Podocarpus(Podocarpaceac) ${ }^{* *}$ & - & - & - & 3 & - \\
\hline & Astronium (Anacardiaceae) \#* & - & - & 1 & - & - \\
\hline & cf. Anacardium (Anacardiaceae) \#* & - & - & 1 & - & - \\
\hline & tipo Arecaceae * & - & 1 & - & - & 2 \\
\hline & cf. Cactaceae * & - & - & 1 & - & 1 \\
\hline & cf. Maytenus (Celastraccac) * & - & - & - & - & 1 \\
\hline & cf. Dalechampia \#* & - & - & 1 & - & - \\
\hline & cf. Copaifera (Fabaceae-Caesalpionoideae) \#* & - & - & - & 1 & - \\
\hline & Fabaceae-Mimosoideae * & - & - & - & - & 1 \\
\hline & tipo Moraceae/Urticaceac* & - & - & - & - & 4 \\
\hline & Passiflora (Passifloraceac) \#* & - & - & - & 1 & - \\
\hline & tipo Malvaceae * & 2 & - & - & - & - \\
\hline & tipo Amaranthaceae/Chenopodiaceae $* / * *$ & - & - & - & 2 & - \\
\hline & tipo Asteraceae * & - & - & - & 2 & - \\
\hline & tipo Poaceac ** & 1 & 1 & 2 & 13 & 1 \\
\hline & tipo Gomphrena ( $\wedge$ maranthaccac) * & 1 & - & - & 5 & 3 \\
\hline & cf. Rubiaceac * & - & - & - & 4 & - \\
\hline & tipo Cucurbita sp.\#* & - & - & - & 5 & - \\
\hline & tipo Ipomoea $\mathrm{sp} . \#^{*}$ & 4 & & - & 3 & 1 \\
\hline & tipo Manihot sp.\#* & - & l & 1 & - & 2 \\
\hline & tipo Gossypium sp.\#* & 1 & - & - & 3 & 2 \\
\hline & Granos de polen Indeterminables & 3 & - & - & 19 & 19 \\
\hline \multirow{26}{*}{ 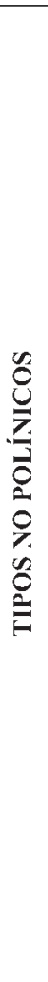 } & Anthoceros (Anthocerothaceae) & - & - & - & 1 & - \\
\hline & Espora monolete & 1 & 5 & 6 & 11 & 8 \\
\hline & Acrostichum (Ptcridaccac) & - & - & - & 2 & 1 \\
\hline & cf. Anemia (Schizaeceae) & - & - & - & 1 & - \\
\hline & Asplenium (Polypodiaccac) & - & - & - & - & 1 \\
\hline & cf. Azolla (Azollaceae) & 1 & - & - & - & - \\
\hline & Blechmum (Blechnaceae) & - & 1 & 1 & 5 & 2 \\
\hline & cf. Danaea (Marattiaceae) & - & - & - & - & 2 \\
\hline & tipo Polypodiaccac & 2 & 3 & 3 & - & - \\
\hline & Selaginella (Selaginellaceae) & - & 2 & - & - & - \\
\hline & Botryococcus & 9 & 2 & - & 9 & - \\
\hline & cf. Acrodictys & - & - & - & 2 & 2 \\
\hline & tipo Alternaria & 5 & - & - & 15 & 13 \\
\hline & tipo Curvularia & 1 & - & - & - & 3 \\
\hline & tipo Puccinia & 5 & 3 & 2 & 24 & 4 \\
\hline & EV1-001 & - & 2 & 3 & - & 1 \\
\hline & Gelasinospora & 1 & 6 & 11 & 2 & 7 \\
\hline & Glomeromycota & 4 & 3 & 39 & 36 & 15 \\
\hline & tipo Meliola & 1 & - & - & 1 & 1 \\
\hline & Microthyrium & - & 1 & 3 & 1 & - \\
\hline & tipo Cercophora & 1 & - & - & - & - \\
\hline & tipo Sordariaceae & 7 & 2 & 3 & 31 & 37 \\
\hline & cf. Spegazzinia & 1 & - & - & 2 & 1 \\
\hline & Tricellaesporonites & - & - & - & 4 & - \\
\hline & cf. Ustilago maydis & 1 & 1 & - & - & - \\
\hline & tipo Xylariaceae & - & - & - & 3 & - \\
\hline & Suma polínica & 52 & 34 & 78 & 211 & 135 \\
\hline & $\mathrm{N}^{\mathrm{N}}$ taxones & 20 & 14 & 15 & 29 & 26 \\
\hline
\end{tabular}

Fig. 5. Datos palinológicos de las muestras cerámicas y sedimentos. 


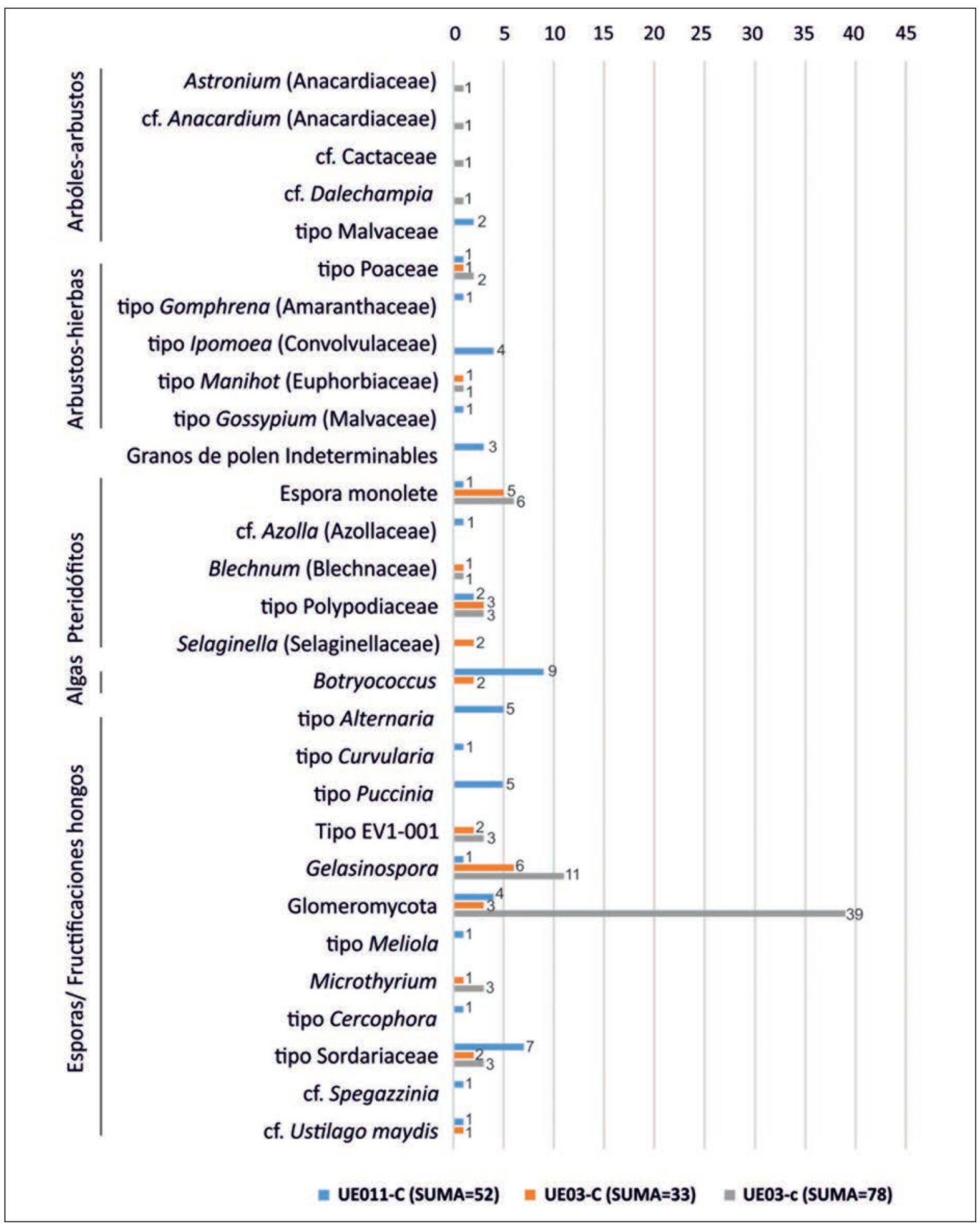

Fig. 6. Frecuencia polínica absoluta de los fragmentos cerámicos. 


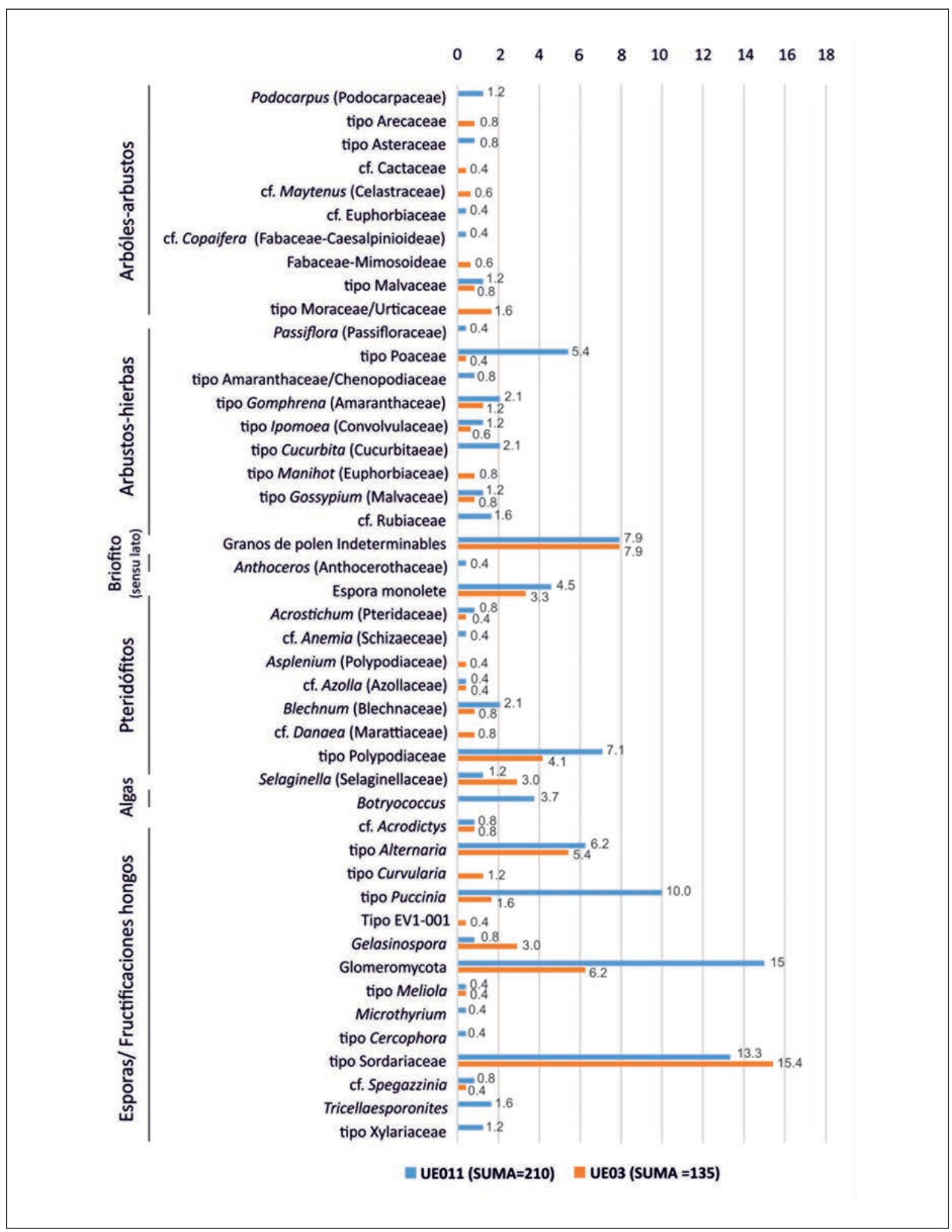

Fig. 7. Porcentaje polínico de los sedimentos internos a las vasijas (muestras-control). 
recuperados de residuos secos (i.e. adheridos a superficie de material lítico o cerámico) normalmente es bajo (Shafer y Holloway 1979 apud Bryant y Hall 1993).

En este contexto, fueron recuperados e identificados un total de 47 taxones: 28 taxones (10 tipos polínicos y 18 no polínicos) en los fragmentos cerámicos y 44 taxones (19 tipos polínicos y 25 no polínicos) en los sedimentos (figs. 5-7). Hubo preservación diferencial, variando de buena entre algunos tipos esporo-polínicos y microhongos, y regular a mala en algunos casos, como los granos de polen indeterminables. La buena preservación de los tipos esporo-polínicos condicionó la identificación taxonómica de familias y géneros (figs. 11-14; 16-17); mientras que la preservación mala no permitió una identificación taxonómica precisa, visto los granos de polen indeterminables (Burjachs et al. 2000). Este factor se aplica dada la naturaleza de los suelos arqueológicos. La descripciones sedimentológicas apuntan depósitos arenosos-arcillosos, resultantes de procesos de lixiviación severos, causados por la intervención humana a lo largo del s. XX (comum. pess. con poblaciones modernas en la zona). En general, los suelos ácidos aceleran la oxidación, lo que favorece la preservación diferencial y posibles sobre-representaciones de algunos palinomorfos (Dimbleby 1985). El propio autor advierte que no hay una solución única para este problema y que debe haber diferentes posibles interpretaciones en base a los métodos de investigación utilizados. Según Havinga (1964-1984) apud Bryant y Hall (1993), la composición química de la exina también representa un factor relevante en contextos arqueológicos, visto que la capacidad de preservación polínica está directamente asociada a altas concentraciones de esporopolenina en detrimento a la celulosa.

\section{EL ESPECTRO POLÍNICO DE LOS FRAGMENTOS CERÁMICOS}

El espectro polínico recuperado de las cerámicas sugiere algunos aspectos culturales de las poblaciones alfareras, sobre el uso y función de esos artefactos. La recuperación polínica fue relativamente baja en relación a los sedimentos analizados (figs. 5-6). Sin embargo las bajas concentraciones polínicas no deben ser motivo de rechazo en depósitos arqueológicos (Bryant y Hall 1993). En el contexto de la unidad arqueológica UE03, (a) la vasija grande exhibe los tipos herbáceos (tipo Poaceae [1], Blechnum [1], Polypodium [3] y Selaginella [2]), Botryococcus [2], microhongos patógenos (Microthyrium [1] y cf. Ustilago maydis [1]), simbiontes de plantas (Glomeromycota [3]) y coprófilos (Gelasinospora [6] y tipo Sordariaceae [2]) (figs. 5 y 9). La (b) vasija pequeña, globular presenta los tipos arbustivo-arbóreos (Astronium [1], cf. Anacardium [1], cf. Cactaceae [1] y cf. Dalechampia [1]), herbáceos (tipo Poaceae [2], tipo Ipomoea [4], tipo Manihot [1], Blechnum [1], Polypodium [3] y Microgramma [2]), microhongo patógeno (Microthyrium [3]), simbiontes de plantas (Glomeromycota [39]) y coprófilos (Gelasinospo$r a$ [11] y tipo Sordariaceae [3]) (figs. 5 y 9). En el contexto de la unidad arqueológica UE011, (c) en la vasija grande, piriforme fueron identificados tipos arbustivo-arbóreos (tipo Malvaceae [2]), arbustivo-herbáceos (tipo Poaceae [2], tipo Gomphrena [1] y tipo Gossypium [1]), granos de polen indeterminables, pteridófitos (cf. Azolla [1] y tipo Polypodiaceae [2]), Botryococcus [9], microhongos patógenos (tipo Alternaria [5], tipo Curvularia [1], tipo Puccinia [4], cf. Ustilago maydis [1], cf. Spegazzinia [1] y tipo Meliola [1]), simbiontes de plantas (Glomeromycota [4]) y coprófilos (Gelasinospora [1], tipo Cercophora [1] y tipo Sordariaceae [7]) (figs. 5 y 10).

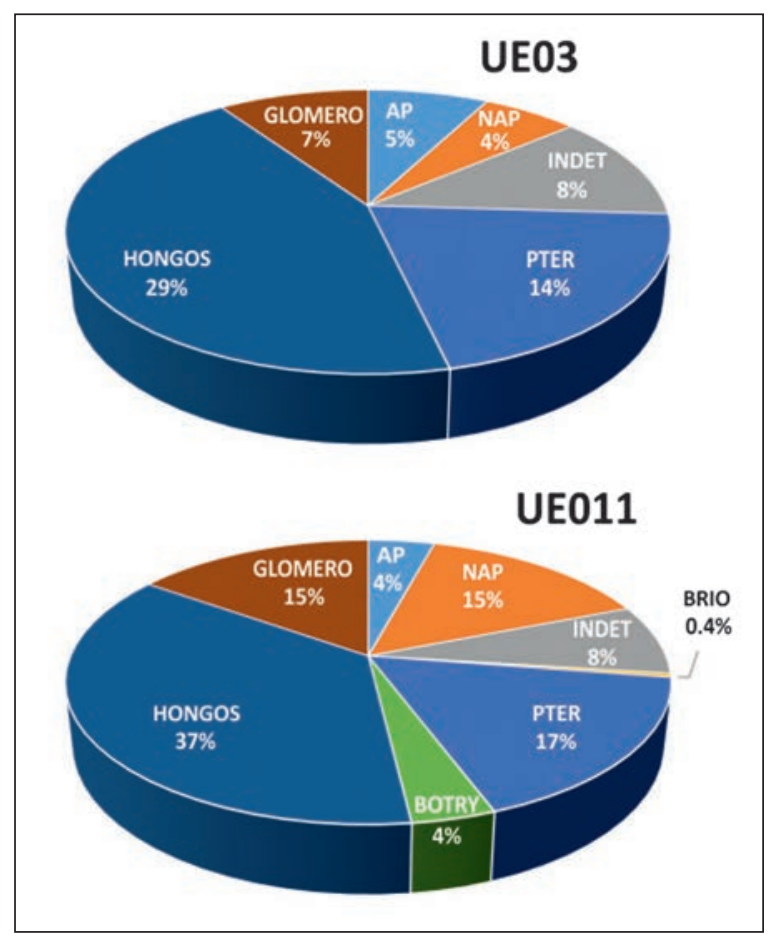

Fig. 8. Distribución polínica porcentual en los sedimentos. Leyenda: AP: polen arbóreo; NAP: polen no arbóreo; INDET: polen indeterminable; PTER: pteridófitos; BRYO: Anthoceros; BOTRY: alga Botryococcus; HONGOS: esporas y fructificaciones de hongos y GLOMERO: hongos Glomeromycota. 

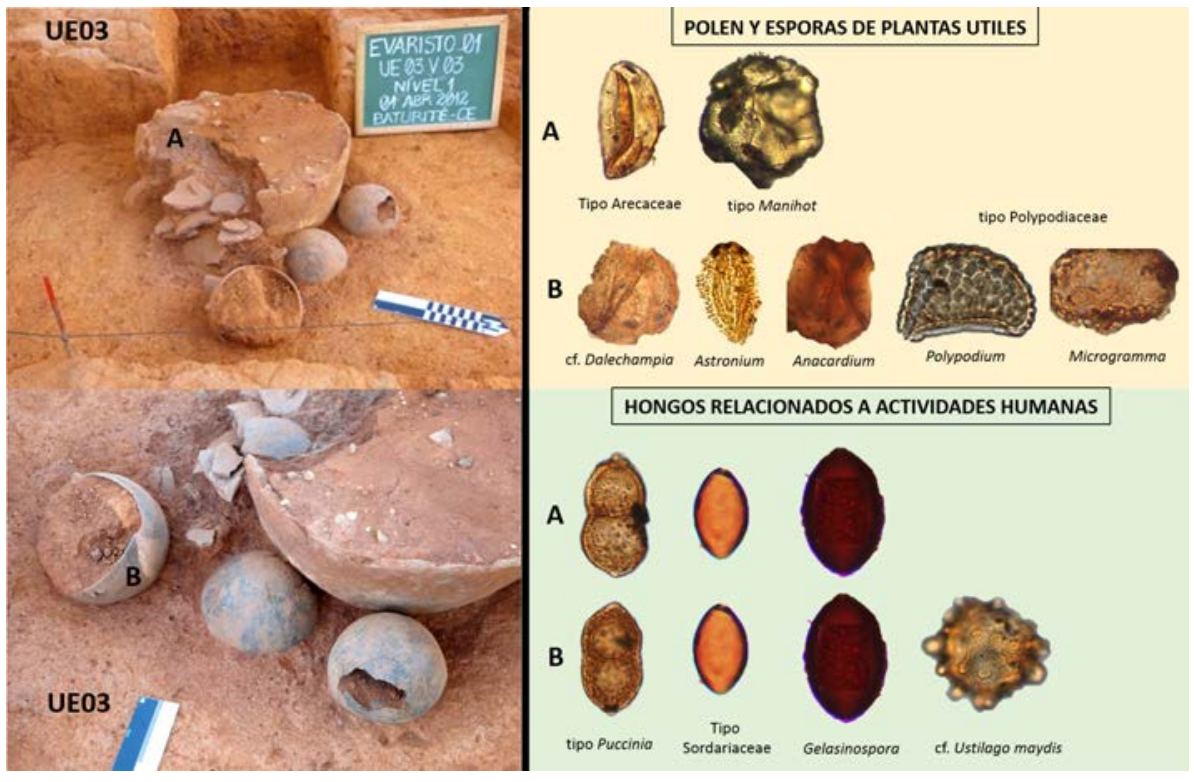

Fig. 9. Palinomorfos identificados en las cerámicas de la UE03.

\section{LAS EVIDENCIAS DE MANEJO Y CULTIVO DE PLANTAS}

Los microvestigios vegetales (i.e., polen, fitolitos) han indicado huellas sobre las prácticas agrícolas durante la Prehistoria en las Américas (Piperno y Pearsall 1998). Como ejemplo del territorio amazónico, la historia de las poblaciones humanas estuvo asociada a los procesos de domesticación de plantas nativas y desarrollo de la subsistencia agrícola de gran porte, lo que contribuyó sustancialmente al crecimiento poblacional y surgimiento de sociedades más complejas (Piperno y Pearsall 1998). Los datos arqueobotánicos en Sudamérica apuntan las tierras bajas (nivel del mar hasta $1500 \mathrm{~m}$ s.n.m.) como zonas favorables al cultivo de la yuca amarga (Manihot esculenta), precedido del camote (Ipomoea batatas), por ejemplo el litoral del Perú, ca. 2600 BP (Pearsall 1992). La yuca necesita de suelos amplios y fértiles, pero su desarrollo ulterior es compatible con sustratos más áridos (Albuquerque y Lucena 1991). Por lo tanto, la preservación de los vestigios botánicos en tierras bajas de bosques tropicales está limitado, debido a la acidez y humedad del suelo, sobre todo los de várzea de la planicie amazónica (Brochado 1977). Hasta ahora, los datos prehistóricos que demuestran el consumo y producción de la yuca amarga (M. esculenta) y sus variedades por parte de las poblaciones precolombinas, conocidos como las Culturas de Floresta Tropical están basados más en las evidencias indirectas (i.e., artefactos cerámicos, líticos y analogías etnográficas) que en las evidencias directas por vestigios vegetales (i.e., polen, carbón y fitolitos) (Brochado 1977; Perry 2005). Sin embargo, los fitolitos y granos de almidón estudiados por Perry (2005) preservados en artefactos líticos en la Amazonia venezolana, muestran el potencial analítico de los microvestigios en la detección de antiguos sistemas de producción agrícola. Las evidencias directas del manejo de plantas y concentración de especies útiles, así como procesos de construcción del paisaje, fueron registradas en la Caverna da Pedra Pintada (Pará), alrededor de $700 \mathrm{BP}$, a través de la abundancia y diversidad de vestigios de palmeras, plantas naturales fructíferas (taperebá-Spondias mombin, maracujá-do mato-Passiflora nítida, anacardo o caju-Anacardium occidentale, jeriváSyagrus cocoides y otros) y cultivadas (maíz-Zea mays y calabaza-Cucurbita sp.) (Scheel-Ybert et al. 2010).

El polen de plantas cultivadas recuperado de las cerámicas del Evaristo I (yuca-tipo Manihot, camote-tipo Ipomoea y algodón-tipo Gossypium) (figs. 9-13) justifican la hipótesis de que los grupos alfareros desarrollaran las prácticas agrícolas alrededor de sus viviendas, con permanencia en la región. Las poblaciones indígenas amazónicas modernas fijan quintais (huertos o jardines) como un espacio alrededor de las casas destinado al cultivo de plantas, en general sin presencia de árboles de gran porte, lo que justifica la presencia de esas plantas (Amoroso y Geli 1988). El registro del polen de palmera (tipo Arecaceae) y árboles típicos de bosques secundarios (tipo Moracae-Urticaceae) junto con las plantas cultivadas 
sugiere el manejo de vegetales y un posible proceso de construcción del paisaje en el Evaristo I (fig. 14). Independiente de las evidencias directas de prácticas agrícolas abordadas en este trabajo, también fueron recuperados en el Yacimiento una gran cantidad de artefactos líticos (i.e., hachas de piedra pulida, lascas y otros) (fig. 3 ). Estos artefactos probablemente fueron utilizados como herramientas para la captación de recursos de origen animal y vegetal, incluyendo la apertura de espacios forestales para la introducción de los cultivos.

Los microhongos tipo Alternaria, Curvularia y Puccinia reflejan el cultivo de plantas como el maíz (Zea mays), el algodón (Gossypium sp.), el camote (Ipomoea batatas) y otros (Gelorini et al. 2011) (figs. 9 y 10). Spegazzinia vive en las hojas y tallos muertos del maíz (Zea mays), de Andropogon y otras gramíneas (Gelorini et al. 2011). Gelasinospora también se presenta en la madera deteriorada o carbonizada, indicando sucesivos incendios o restos de madera descartada, no seleccionada para el uso (figs. 9 y 10). Xylariaceae puede estar relacionada con un aumento en las poblaciones de animales domésticos vivos o muertos por los incendios provocados para la caza o para los cultivos (Gelorini et al. 2011) (fig. 16). Glomeromycota (figs. 16-17) es un indicador de suelos o detritos vegetales húmedos, por su asociación a raíces de caña de azúcar ( $\mathrm{Sa}$ ccharum officinarum), camote o plantas pioneras como Panicum racemosum. Los datos polínicos refuerzan las otras evidencias de sistemas agrícolas y probable sedentarismo. Esos datos juntos suelen indicar el tiempo de permanencia de las poblaciones alfareras en la zona.

\section{DIETA Y SUBSISTENCIA}

El conocimiento sobre el modo de vida, sedentarismo y hábitos alimenticios de los grupos indígenas prehistóricos está basado fundamentalmente en las evidencias indirectas de cultivo y manejo de plantas (i.e., hallazgos cerámicos y líticos, datos etnográficos) (Perry 2005). Entretanto, los relatos etnohistóricos sumado a la buena preservación de los vestigios arqueobotánicos son la base para las aproximaciones sobre las interacciones entre las poblaciones humanas y las plantas (Scheel-Ybert et al. 2010).

Los relatos de cronistas de los ss. XVI y XVII sobre los indígenas de la Provincia de Ceará reinterpretados por Fernandes (1989) apud Corrêa-da-Silva (2010), describen los Tupinambá (Tupiguarani) viviendo en zonas interiores post-contacto europeo con aspectos culturales más elaborados, sobre el acto de dormir en redes, la caza y pesca, y producción de arcos y flechas. Vivían del cultivo intensivo de la yuca y practicaban la antropofagia. Sus aldeas poseían malocas u ocas distribuidas en forma circular o cuadrangular, y por el centro una zona destinada a actividades sociales. Los indígenas Tremembés ocuparon el litoral cearense. Sus aspectos culturales involucraban el nomadismo, dormían sobre la arena, y su industria cultural era poco elaborada, portando pocos utensilios domésticos, como ollas de barro y cabaça para el almacenaje de agua. Su subsistencia era compuesta por elementos de la fauna (caza y pesca) y del cultivo del maíz, yuca y fríjol, desarrollada en huertos cercanos a sus viviendas (Santos y Oliveira 2012).

La preservación del polen relacionado a los tubérculos (yuca-tipo Manihot, camote-tipo Ipomoea), legumbres (calabazas), el maíz y otras céspedes y plantas naturales fructíferas (palmeras-tipo Arecaceae, caju-cf. Anacardium y maracujá- cf. Passiflora) en las cerámicas del Evaristo I (figs. 9-14) reflejan una dieta diversificada por parte de los grupos alfareros, aportando datos relevantes sobre la captación de los recursos vegetales. En el mismo contexto funerario, para las unidades arqueológicas excavadas, fueron recuperados numerosas cantidades de dientes humanos presentando lesiones cariosas. Esas enfermedades suelen resultar del alto consumo de almidones y azúcares. También fueron identificadas lesiones cavitarias severas
Fig. 10. Palinomorfos identificados en la cerámica de la UE011.

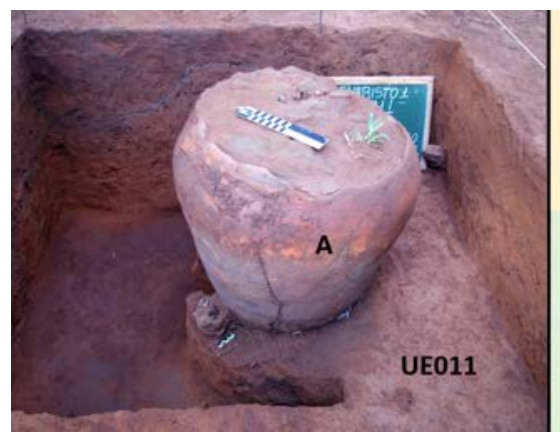

A

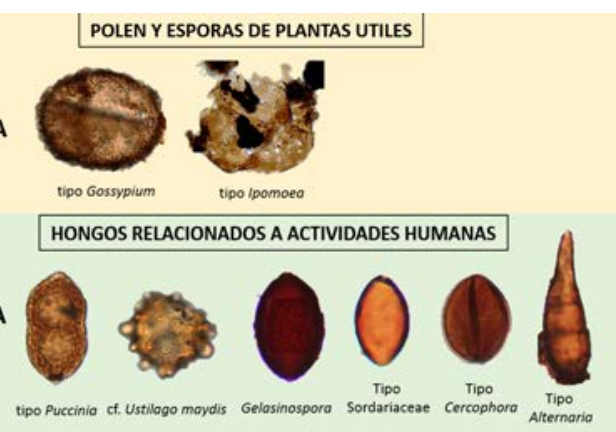




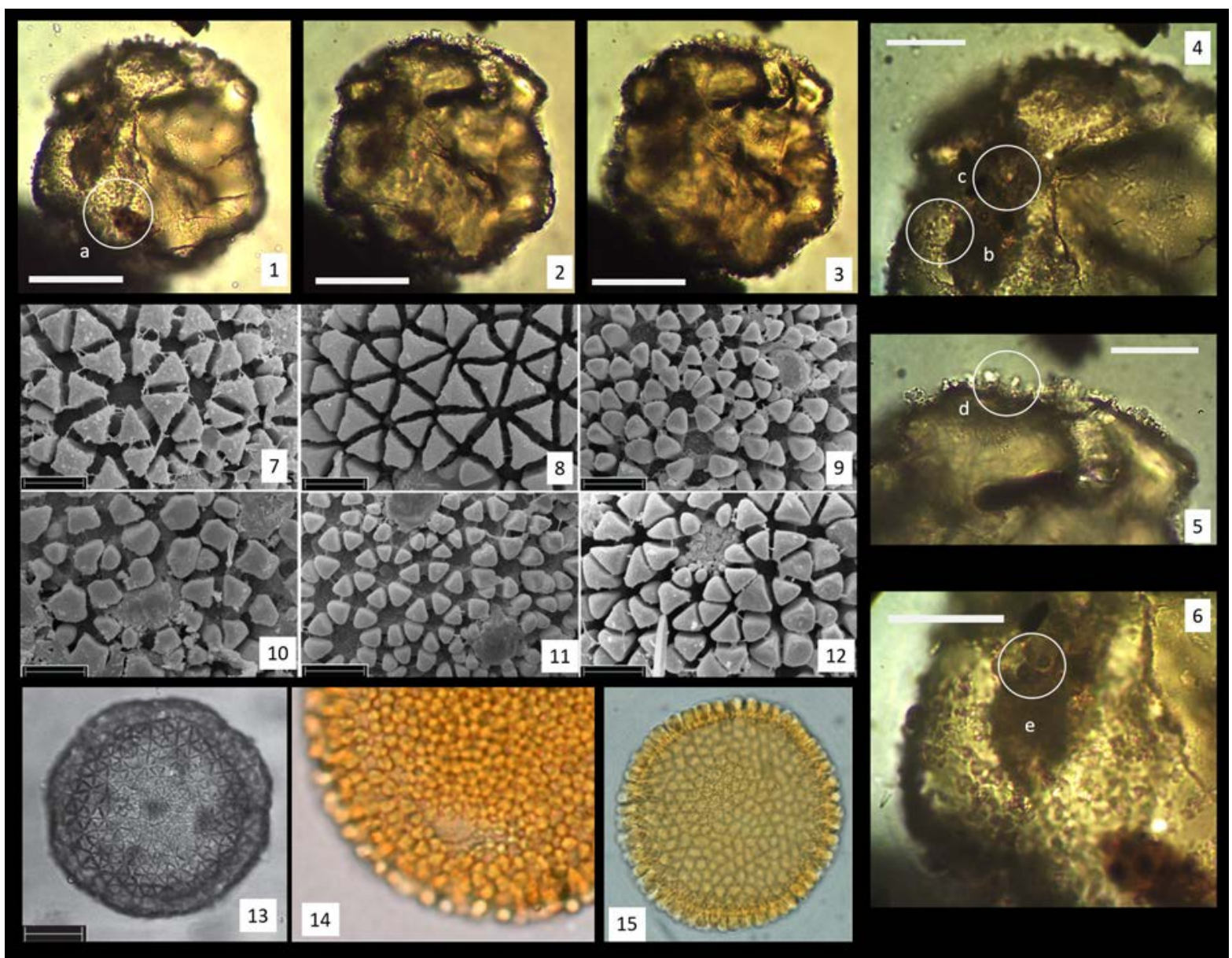

Fig. 11. Microfotografias del tipo polínico Manihot (cerámica de la UE03): 1-3: vista proximal, vista distal y corte óptico (400x, $20 \mu \mathrm{m}$ ). (1a) Detalle de pauta crotonoide (rosetas). 4(b-c): aperturas (poros, pantoporado) (1000x, $20 \mu \mathrm{m}) .5(\mathrm{~d})$ : elemento accesorio de la exina (pilos, pilada) $(1000 \mathrm{x}, 20 \mu \mathrm{m}) .6(\mathrm{e})$ : pauta exínica crotonoide (1000x, $20 \mu \mathrm{m})$. Comparaciones: 7-11: microfotografias de las especies naturales de Manihot (M. labelifolia; M. dichotoma; M.tomentosa; M. violacea; M. cecropiaefolia) (10 $\mu \mathrm{m})$ (Vieira et al. 2012). 12. Micrografia de barrido de la especie cultivada (Manihot esculenta) $(10 \mu \mathrm{m})$ (Vieira et al. 2012). 13. Aspecto general del polen de M. esculenta $(50 \mu \mathrm{m})($ Vieira et al. 2012). 14. Cnidoscolus chaya (detalle de la ornamentación de la exina; pantoporado; 85-100 $\mu \mathrm{m}$ ) (Bush y Weng 2007). 15. Aspecto general del polen de Croton bilbergianus (detalle de la exina; inaperturado; 50-55 $\mu \mathrm{m}$ ) (Bush y Weng 2007).

resultantes del probable consumo de alimentos duros como semillas o granos (Silva et al. 2014). Las investigaciones arqueobotánicas de los sambaquis brasileños sugieren el manejo y cultivo de tubérculos como el camote (Ipomoea patatas) y el cará (Dioscorea sp.), raíces ricas en almidón como complemento de la dieta de las poblaciones costeras prehistóricas (Scheel-Ybert 2001; Wesolowksi 2008). De acuerdo con estos investigadores, la asociación entre el consumo constante de un alimento de origen vegetal y la baja diversidad de fuentes de hidratos de carbono incorporados a la dieta suele indicar prácticas de horticultura, aunque incipiente, para esos grupos humanos.
Por otra parte, los altos porcentajes de Gelasinospora, tipo Cercophora y tipo Sordariaceae, comúnmente encontrados en el estiércol humano y de otros animales sugieren actividades de subsistencia agrícola, caza y domesticación de animales (Gelorini et al. 2011; Van Geel et al. 2011) (figs. 9-10).

\section{USO Y FUNCIÓN DE LA CERÁMICA}

Los vestigios arqueobotánicos son potencialmente importantes cuando se busca conocer la función o uso de determinado artefacto (Holloway y Bryant 1986; Arendt 2004). Respecto de las investigaciones sobre la cerámica 
arqueológica brasileña, existen diversos hallazgos y fuentes bibliográficas sobre el material cultural, la tecnología y comportamiento socio-económico de las sociedades alfareras prehistóricas (Prous 1992; Oliveira 2003). Según estos autores, la producción de cerámica por parte de los grupos humanos estaría directamente asociada al sedentarismo y al cultivo de vegetales para subsistencia.

Los análisis polínicos de la vasija grande de la UE03 indican un probable uso de este recipiente en contexto doméstico, además del contexto funerario. El hongo cf. Ustilago maydis (fig. 9) refleja probables zonas de cultivo alrededor de las zonas de enterramiento (Da Ponte 1967). La presencia del polen de gramíneas (tipo Poaceae) y cf. Ustilago maydis sugieren un probable uso de los recipientes para el almacenamiento de los alimentos cultivados en la zona, en este caso el maíz (Zea mays), relacionados a la recogida post-cosecha o a la escasez de comida durante periodos más secos. Botryococcus y los fragmentos de carbón de la misma unidad UE03 sugieren un posible uso en el almacenaje de agua o preparación de alimentos cocidos/hervidos. Según Oliveira y Pedroza (2014), la principal fuente de agua para el abastecimiento de las comunidades vivientes actualmente en la región del Maciço de Baturité es por medio de fuentes naturales $\mathrm{u}$ ojos d'agua, que afloran en las porciones más rebajadas del terreno, a través de una red fluvial dedrítica, dificultando las actividades agrícolas modernas. Si extrapolamos estos datos para los últimos siglos se puede confirmar las actividades de recolecta de agua de fuentes medio lejanas a las zonas de hogar, utilizando los recipientes cerámicos para esa finalidad. En la cerámica fue registrado el hongo Microthyrium, patógeno del anacardo o caju (Anacardium occidentale), sugiriendo su probable uso también para esos fines. Las esporas de hongos relacionadas con el estiércol humano y de otros animales, como Gelasinospora y tipo Sordariaceae, son bastante comunes en yacimientos arqueológicos (Cugny et al. 2011; Gelorini et al. 2011). En este contexto indican que las zonas de enterramiento posiblemente eran cercanas a las zonas de hogar (fig. 19). Gelasinospora también sobreviene en la madera carbonizada, indicando hogueras de contexto doméstico o funerario, o sucesivos incendios tanto para los cultivos como para la caza (Gelorini et al. 2011) (figs. 9-10). En esta vasija se registró un enterramiento primario con el esqueleto bien preservado, junto a material lítico, fragmentos cerámicos diversos, sedimentos con cenizas, carbón, y restos de fauna y flora (Silva et al. 2014). La presencia de un recipiente con la función de "tapar" o "cerrar" una urna principal conteniendo el cuerpo denota el carácter de sepultura primaria en la deposición funeraria (Oliveira y Pedroza 2014). Martin (1994) afirma que en general, la misma cerámica usada para fines domésticos servía para fines funerarios. La autora registra gran cuantidad de yacimientos funerarios conocidos como aribés y/u igaçabas, en el NE de Brasil, conteniendo huesos humanos inhumados, o cubiertos por recipientes cerámicos.
Fig. 12. Microfotografías del tipo polínico Gossypium (cerámica de la UE011): 1. Aspecto general del grano en microscopía óptica. (1a): exina equinada (espinas). (1b): detalle del poro (pantoporado) (1000x, $20 \mu \mathrm{m})$. Comparaciones: 2-4: microfotografías de la especie cultivada Gossypium barbadense (Saba 2007; Jones y McCurry 2012). (2P): espinas. (2O): poros $(1000 \mathrm{x}, 10 \mu \mathrm{m})$. (3-4): micrografia de barrido $(10 \mu \mathrm{m})$. 5-6: microfotografías de la especie cultivada Gossypium hirsutum (Saba 2007). (5-6): microscopía de barrido $(10 \mu \mathrm{m})$.

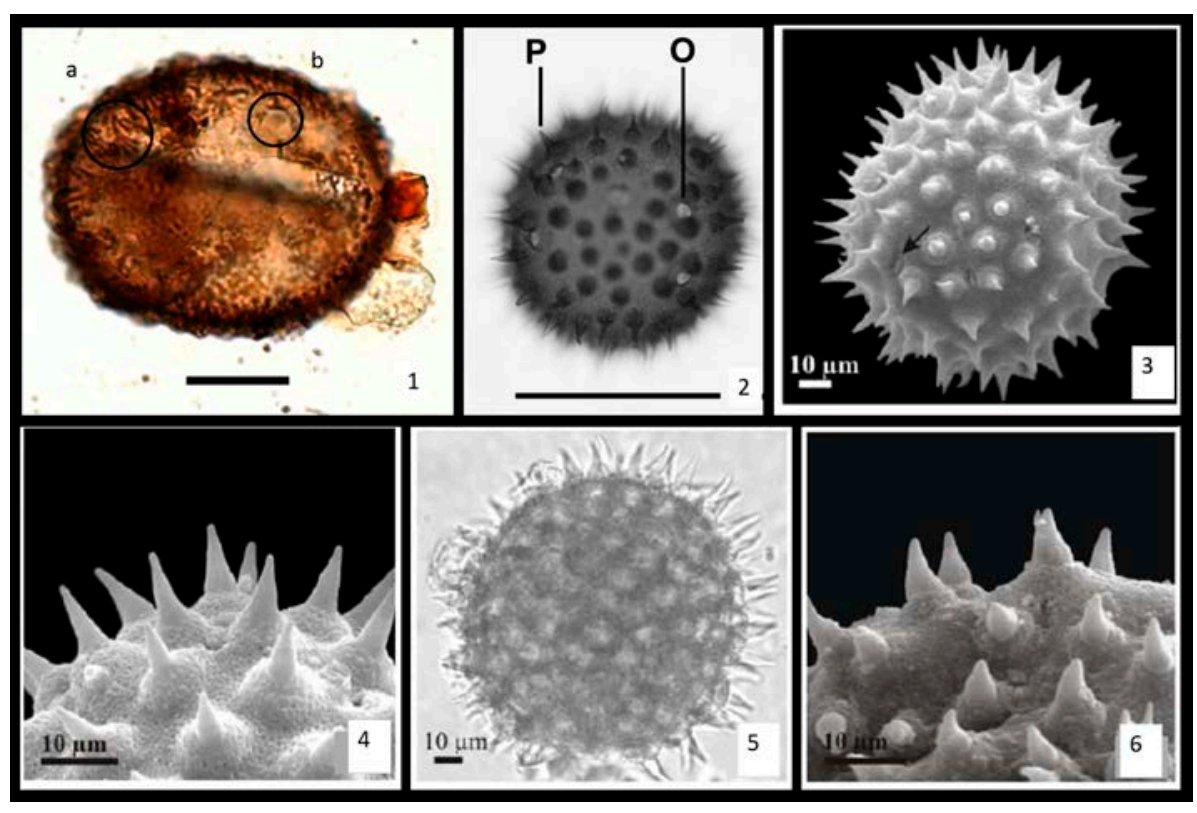




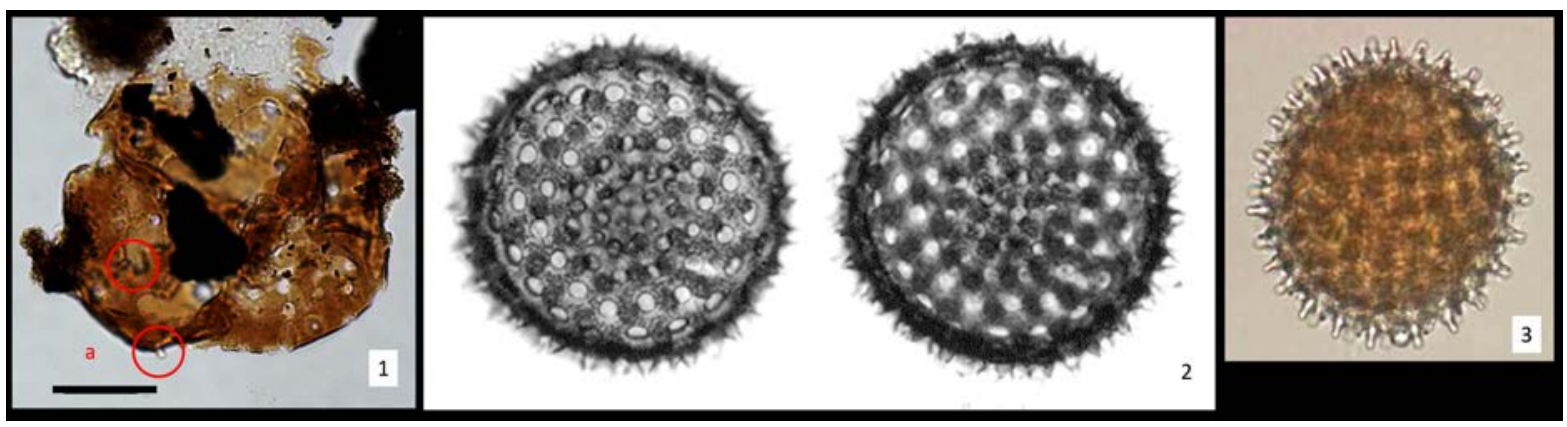

Fig. 13. Microfotografías del tipo polínico Ipomoea (cerámica de la UE011): 1. Aspecto general del grano en microscopía óptica. (2): aspecto general de la especie cultivada Ipomoea batatas (1000x) (Roubik y Moreno 1991) (3): aspecto general de la especie autóctona I. triloba (400x) (Jayeola y Oladunjoye 2012).

El análisis polínico de la vasija pequeña, globular de la UE03 refleja su probable uso en contexto funerario (fig. 9). Esta vasija fue puesta al lado de la urna funeraria, representada por la vasija grande de la UE03. La mayoría de los pólenes recuperados en la vasija presentan polinización zoófila (Astronium, cf. Anacardium, cf. Cactaceae, cf. Dalechampia, tipo Ipomoea, tipo Manihot) (fig. 9 ). De este modo, podemos inferir sobre una probable selección de plantas útiles por parte de las poblaciones humanas para uso funerario, asociadas a algún tipo ritual $\mathrm{u}$ ofrenda. La presencia del polen de plantas cultivadas (tipo Ipomoea y tipo Manihot) también indica zonas de cultivo alrededor de las zonas de hogar y zonas de enterramiento. El registro del polen de caju (cf. Anacardium) indica la explotación de plantas arbóreas fructíferas, que puede estar asociado al consumo doméstico de bebidas hechas a partir de la planta (figs. 9 y 12). El anacardo o caju es endémico de la Provincia de Ceará, y es bastante consumida por poblaciones indígenas modernas. El viño de caju (Anacardium occidentale) fermentado (mocorocó) es consumido durante el ritual del Torém, un tipo de expresión cultural de danza de los indígenas Tremembés modernos (Valle 2005). Otros hallazgos arqueológicos recuperados de la UE03 nos confirman una especie de enxoval o mobiliario funerario, que acompañaban a los muertos, como fragmentos cerámicos, pipas y adornos líticos. Según Silva (2005), en las prácticas funerarias registradas en la cultura Guarani en la actual Provincia de São Paulo (SE de Brasil), el cuerpo y huesos eran depositados en el interior de una vasija cerámica y cubiertos con otra vasija más pequeña, cuyas utilizaciones anteriores remetían al uso doméstico. En las tumbas se colocaban pequeñas vasijas con alimentos y bebidas alrededor de la grande. Los enterramientos ocurrían cerca de las viviendas.
En el espectro polínico de la vasija grande, piriforme de la UE011 sugiere su uso en contexto doméstico (figs. 10 y 13). La presencia y diversidad de hongos patógenos (tipo Alternaria, tipo Curvularia, tipo Puccinia, cf. Ustilago maydis, cf. Spegazzinia y tipo Meliola) de plantas cultivadas como el algodón (Gossypium spp.), el maíz (Zea maiz), el camote (Ipomoea patatas) y otros tubérculos y plantas naturales como la césped común (Gelorini et al. 2011) indica probable función de almacenamiento para esos recipientes (fig. 13). durante los periodos más secos. Spegazzinia y Puccinia son considerados hongos patógenos de las hojas y tallos el maíz (Peixoto Júnior 2011; Gelorini et al.2011). Botryococcus indica que esos recipientes algunas veces servían para almacenar agua o directamente para cocinar alimentos (fig. 9). Glomeromycota indica la diversidad de plantas naturales y cultivadas en la zona (Wang y Liu 2006; Van Geel et al. 2011) (fig. 14).

Los aspectos culturales de la cerámica Pintada de la Subtradición Meridional Tupi-Guarani identificados por Lima Rocha (2009), revelan que los recipientes cerámicos han tenido doble función. Por el aspecto doméstico, tenían función de contener las bebidas fermentadas, como la cerveza o cauim. En otro aspecto, el mismo recipiente podría servir como receptáculo para los muertos. De acuerdo con los estudios de Brochado (1991) y Prous (1992), la utilización de la esas vasijas suelen están relacionadas en un primer aspecto al acto de beber o consumir alimentos líquidos. Los recipientes globulares esféricos servían para la preparación de alimentos hervidos, técnica poco común a los de esa cultura. Un segundo aspecto relaciona el consumo de bebidas a los rituales funerarios. Unos recipientes con tales características piriformes fueron detectados como urnas funerarias en un yacimiento filiado a la Tradición Aratu, que ocuparon el 
litoral S del NE de Brasil, cerca de 670-650 BP(Etchevarne 2012). En todo caso, por la ausencia o no preservación de vestigios humanos (huesos y dientes) en vasija (piriforme) de la UE011, no se puede afirmar el carácter funerario.

\section{EL SIGNIFICADO CULTURAL DE LAS PLANTAS ÚTILES}

En general, las plantas constituyen un reflejo de la cultura, ideología y tecnología que han existido a lo largo de la historia humana (Bates 1985 apud Montani 2012). Estos datos culturales son las huellas de las interacciones entre las poblaciones humanas y las plantas, desde el punto de vista ecológico y económico (Hastorf 1999). Entre los aspectos culturales del uso doméstico de plantas por las sociedades humanas prehistóricas incluye: el procesamiento de alimentos, y la recogida de madera como combustible para la cocción de alimentos (Hastorf 1999). El manejo de vegetales, incluyendo especies productoras de tubérculos y árboles fructíferos fueron las principales fuentes de alimentación entre las poblaciones prehistóricas de la zona costera brasileña (Scheel-Ybert 2001; Wesolowski 2008).

La mayoría de las plantas identificadas en los fragmentos cerámicos son un reflejo de las actividades humanas en contexto doméstico y funerario, en los espacios ocupados por los grupos alfareros. Los hallazgos polínicos indican plantas cultivadas directamente asociadas a la dieta de las antiguas poblaciones alfareras, tal y como se ha indicado anteriormente. Sin embargo, hay registro de otras plantas manipuladas por esos grupos, cuyas múltiples funciones y usos por poblaciones indígenas modernas en territorio sudamericano son presentadas en la fig. 15. Según los relatos etnobotánicos de Amoroso y Geli (1988), el helecho conocido por guaribinha (Polypodium decumanum) es usado como planta curativa de enfermedades pulmonares por los caboclos del bajo río Amazonas. Los indígenas Palikur, de Guyana Francesa, la usaban para curar la tos de guariba o coqueluche por los indígenas Wayãpi (Amoroso y Geli 1988). Se registra también polen de árboles fructíferos (cf. Anacardiumсаju) (fig. 9), planta originaria del NE brasileño, especialmente la Provincia de Ceará (Pimentel 1988). Conforme las descripciones de Valle (2005), en un estudio de los indígenas Tremembés modernos: Durante el ritual de danza, o Torém, el cacique sirve al grupo una bebida llamada morococó, una especie de vino de caju fermentado. Según Amoroso y Geli (1988), las plantas fructíferas como el anacardo o caju y el maracujá (Passiflora spp.) poseen valor terapéutico (figs. 9-10; 14). Estos datos también contribuyen con la hipótesis del manejo y selección de plantas naturales en la zona arqueológica.

Fig. 14. Microfotografías de los tipos polínicos recuperados de los sedimentos: 1. tipo $\mathrm{Cu}$ curbita (400x). 2. cf. Copaife$r a(1000 \mathrm{x}) .3$. tipo Arecaceae $(400 x)$. 4. tipo Malvaceae $(1000 x)$. 5. tipo Cactaceae $(1000 x)$. 6. tipo Poaceae (1000x). 7. Tipo Amaranthaceae-Chenopodiaceae (1000x). 8. Tipo Rubiaceae (1000x). 9. Podocarpus (1000x). 10. Fabaceae-Mimosoideae (1000x). 11. Passiflora $(1000 \mathrm{x}) .12$. Tipo Gomphrena (1000x).

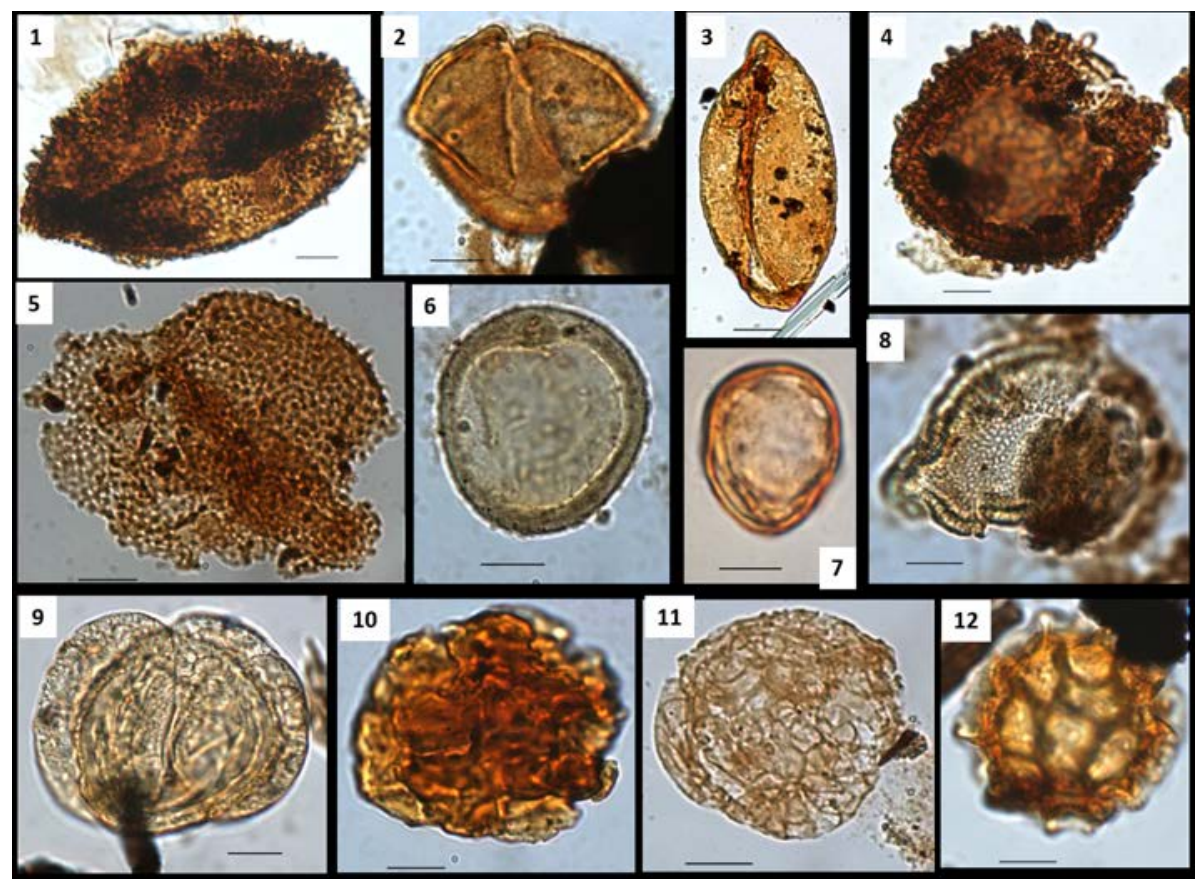


Aline Gonçalves de Freitas, José Sebastián Carrión García, Santiago Fernández Jiménez, Igor Pedroza, Caroline Fernandes Caromano, Leandro Mathews Cascón, Gina Faraco Bianchint, Sergio Francisco Serafim Monteiro da Silva, Neuvania Curty Ghetti, Claudia Alves de Oliveira

\begin{tabular}{|c|c|c|c|c|}
\hline \begin{tabular}{|l|} 
TIPOS \\
POLÍNICOS
\end{tabular} & OCURRENCIA & $\begin{array}{l}\text { AFINIDAD BOTÁNICA/ } \\
\text { NOMBRE VULGAR }\end{array}$ & DATOS MORFOLOGICOS & DATOS ETNOBOTANICOS $^{*}$ \\
\hline $\begin{array}{l}\text { tipo Arecaceae } \\
\text { (fig. 14) }\end{array}$ & $\begin{array}{l}\text { UE03 - vasija } \\
\text { grande }\end{array}$ & $\begin{array}{l}\text { Euterpe edu/is (palmiteiro, } \\
\text { juçara, içara); Syagrus spp. } \\
\text { (ouricuri, catolé); Orbygnia } \\
\text { martiniana (babaçu) }\end{array}$ & \begin{tabular}{|l|} 
Descripciones: mónade, \\
medio (37x 20 um), \\
heteropolar-radiosimétrico, \\
monosulcado, exina escabrada- \\
verrucada(?) en vista \\
ecuatorial. Referencias: \\
Bauermman et al. $(2010)$
\end{tabular} & $\begin{array}{l}\text { alimentício, medicinal, tecnológico, comercial y ritual. } \\
\text { Plantas frutíferas fornecedoras de aceite, cera y fibras } \\
\text { usadas por diversas poblaciones indigenas modernas: } \\
\text { Fulni-ó (Pernambuco) y Tremembé (Ceará). Las fibras } \\
\text { de palmeras y hojas de Ouricuri fueron ampliamente } \\
\text { usadas en ritos funerarios en Nordeste de Brasil. Es } \\
\text { común los hallazgos de fibras estiradas para envolver } \\
\text { cuerpos o cubrir el suelo del sepultamiento y el uso de } \\
\text { cestas para enterrar los niños Referencias: Martin } \\
\text { (1994); Porto Alegre (2000); Rufino et al. (2008) }\end{array}$ \\
\hline \begin{tabular}{|l|} 
Astronium \\
(Anacardiaceae) \\
(fig. 9)
\end{tabular} & $\begin{array}{l}\text { UE03 - vasija } \\
\text { pequeña globular }\end{array}$ & $\begin{array}{l}\text { Astronium fraxinifolium } \\
\text { (Gonçalo-alves) } ; A \text {. } \\
\text { urundeva (aroeira-do- } \\
\text { sertão) }\end{array}$ & \begin{tabular}{|l|} 
Descripción: mónade, medio \\
(42x25 um), isopolar- \\
radiosimétrico, tricolporado, \\
colpo (34 um), exina estriado- \\
reticulada ( 2 um), prolato. \\
Referencias: Roubik y \\
Moreno (1991); Freitas y \\
Carvalho (2012)
\end{tabular} & $\begin{array}{l}\text { medicinal y económico. Ampliamente usado en la } \\
\text { medicina popular del NE brasileño (i.e., Tapeba de } \\
\text { Ceará) y su madera es muy usada en la construcción. } \\
\text { Referencias: Morais et al. (2005) }\end{array}$ \\
\hline $\begin{array}{l}\text { Anacardium } \\
\text { (Anacardiaceae) } \\
\text { (fig. 9) }\end{array}$ & $\begin{array}{l}\text { UE03 - vasija } \\
\text { pequeña globular }\end{array}$ & $\begin{array}{l}\text { Anacardium occidentale } \\
\text { (cajú) }\end{array}$ & \begin{tabular}{|l|} 
Descripción: mónade, grande \\
(55x45 um), isopolar- \\
radiosimétrico, tricolporado, \\
cxina reticulada. Referencias: \\
Roubik y Moreno (1991); \\
Bush y Weng $(2007)$
\end{tabular} & $\begin{array}{l}\text { alimenticio, medicinal y ritualístico. Planta fruetífera } \\
\text { usada por los indígenas Tremembés modernos en las } \\
\text { ceremonias religiosas como el Torém, a partir de la } \\
\text { preparación del mocororó (bebida fermentada de zumo } \\
\text { de cajú). Presente en varias lruterías o pomares } \\
\text { caseros de las poblaciones indigenas del litoral del } \\
\text { Ceará. Usada también como fármaco por poblaciones } \\
\text { indigenas modcrnas del SE y NE de Brasil (ticrra } \\
\text { indigena Araribóia, Maranhão). En la cultura de los } \\
\text { Xucurú-Ororobá (Pernambuco), la castaña representa } \\
\text { un poderoso talismán contra picada de culebra. Su } \\
\text { madera es muy empleada en la construcción. } \\
\text { Referencias: Amoroso \& Geli (1988); Porto Alegre } \\
\text { (2000); Silva \& Andrade (2002); Coutinho et al. } \\
\text { (2002); Boscolo \& Senna Valle (2008) }\end{array}$ \\
\hline $\begin{array}{l}\text { Dalechampia } \\
\text { (Euphorbiaceae) } \\
\text { (fig. 9) }\end{array}$ & $\begin{array}{l}\text { UE03 - vasija } \\
\text { pequeña globular }\end{array}$ & $\begin{array}{l}\text { Dalechampia sp.; } D . \\
\text { scandens (tamiarana); D. } \\
\text { ficifolia (pó-de-mico) }\end{array}$ & \begin{tabular}{|l|} 
Descripción: mónade, grande \\
(62x58 um), isopolar- \\
radiosimétrico, tricolporado, \\
colpo (40 um), exina \\
reticulada, endocingulado. \\
Referencias: Roubik y \\
Moreno (1991); Bush y Weng \\
(2007); Frcitas y Carvalho \\
(2012)
\end{tabular} & $\begin{array}{l}\text { medicinal y ritualístico. Planta útil para los indigenas } \\
\text { Xucuru-Ororobá (Pernambuco), pero también suele } \\
\text { causar la muerte del ganado y picor en la piel } \\
\text { (urticante). Referencias: Silva \&Andrade (2004) }\end{array}$ \\
\hline $\begin{array}{l}\text { tipo Gossypium } \\
\text { (Malvaceae) } \\
\text { (fig. 12) }\end{array}$ & $\begin{array}{l}\text { UE011 - vasija } \\
\text { grande piriforme }\end{array}$ & $\begin{array}{l}\text { Gossypium barbadense } \\
\text { (algodón quebradinho); } G \text {. } \\
\text { hirsutum (algodón mocó); } \\
\text { G. herbaceum (algodón) }\end{array}$ & $\begin{array}{l}\text { Descripción: mónade, grande } \\
\text { (78x78 um), isopolar- } \\
\text { radiosimétrico, pantoporado, } \\
\text { exina equinada. Comentarios: } \\
\text { los pólenes de las especies } \\
\text { salvajes suclen medir menos } \\
\text { que los cultivados. Sin } \\
\text { embargo, el tamaño del polen } \\
\text { de especies cultivadas } \\
\text { actualmente cn NE de Brasil, } \\
\text { como el G. barbadense varían } \\
\text { entre } 77-125 \text { um (ca. } 106 \text { um), } \\
\text { G. hirsutum entre } 77-109 \text { um } \\
\text { (ca. } 94 \text { um), y G. herbaceum } \\
\text { con } 64-99 \text { um (ca. } 80 \text { um). } \\
\text { Referencias: Saba (2007); } \\
\text { Jones y McCurry (2012) }\end{array}$ & $\begin{array}{l}\text { alimentício, medicinal, tecnológico, comercial y } \\
\text { artesanía. Usado por poblaciones indigenas } \\
\text { prehistóricas del Perú, indigenas (Goitacazes. Tupi) y } \\
\text { quilombolas modernas del SE de Brasil y los } \\
\text { Tremembé en el NE de Brasil. G. herbaceumes usado } \\
\text { como anti-inflamatorio cn la medicina popular cn } \\
\text { Maranhão, NE de Brasil). Referencias: Quilter } \text { et al. } \\
\text { (1991); Porto Alegre (2000); Boscolo y Senna Valle } \\
\text { (2008); Madaleno (2011) }\end{array}$ \\
\hline
\end{tabular}




\begin{tabular}{|c|c|c|c|c|}
\hline $\begin{array}{l}\text { TIPOS } \\
\text { POLÍNICOS }\end{array}$ & OCURRENCIA & $\begin{array}{l}\text { AFINIDAD BOTÁNICA/ } \\
\text { NOMBRE VULGAR }\end{array}$ & DATOS MORFOLOGICOS & DATOS ETNOBOTÁNICOS* \\
\hline $\begin{array}{l}\text { tipo Ipomoea } \\
\text { (Convolvulaceae) } \\
\text { (Fig. 13) }\end{array}$ & $\begin{array}{l}\text { UE011 - vasija } \\
\text { grande piriforme }\end{array}$ & Ipomoea batatas (camote) & $\begin{array}{l}\text { Descripción: mónade, grande } \\
\text { (90x90 um), apolar- } \\
\text { asimétrico, pantoporado, } \\
\text { esferoidal, exina equinada. } \\
\text { Comentarios: las especies } \\
\text { salvajes suelen medir entre } \\
\text { (30-40 um) (i.e., I. triloba ca. } \\
32-34 \text { um), con excepción de } \\
\text { I. aquatica (60-62 um), } \\
\text { mientras la especie cultivada } \\
\text { (Ipomoea batatas) mide entre } \\
\text { 112-142 um. Los espinos (3-9 } \\
\text { um) no varian entre los } \\
\text { especimenes salvajes y } \\
\text { cultivados. Referencias: } \\
\text { Roubik y Moreno (1991); } \\
\text { Jayeola y Oladunjoye (2012) }\end{array}$ & $\begin{array}{l}\text { alimenticio y medicinal. Usado por diversas } \\
\text { poblaciones indígenas y quilombolas modernas del SE, } \\
\text { S (Kaingang-Xapecó) y NE brasileño. Referencias: } \\
\text { Haverroth (1997); Boscolo y Senna Valle (2008) }\end{array}$ \\
\hline $\begin{array}{l}\text { tipo Cucurbita } \\
\text { (Cucurbitaceae) } \\
\text { (Fig. 14) }\end{array}$ & $\begin{array}{l}\text { UE0II - } \\
\text { sedimento de la } \\
\text { vasija grande } \\
\text { piriforme }\end{array}$ & $\begin{array}{l}\text { Cucurbita maxima } \\
\text { (calabaza); C. pepo } \\
\text { (calabacin) }\end{array}$ & $\begin{array}{l}\text { Descripción: mónade, grande } \\
\text { ( } 90 x 90 \text { um), apolar- } \\
\text { asimétrico, pantoporado, } \\
\text { esferoidal, exina equinada. } \\
\text { Comentarios: las especies } \\
\text { cultivadas ( C. maxima) } \\
\text { posecn espinas con 5-9 um y } \\
\text { exina } 4 \text { um. Referencias: } \\
\text { Hidalgo y Fernández (1996) }\end{array}$ & $\begin{array}{l}\text { alimentar. Base de la alimentación humana prehistórica } \\
\text { en las Américas, junto con la yuca y el maíz. Hubo } \\
\text { indicios de su domesticación en el S de México ( } 9000- \\
7000 \text { BP). Referencias: Piperno et al. (2000); Bisognin } \\
(2002)\end{array}$ \\
\hline $\begin{array}{l}\text { tipo Manihot } \\
\text { (Euphorbiaceac) } \\
\text { (Figs.9 y 11) }\end{array}$ & $\begin{array}{l}\text { UE03 - vasija } \\
\text { grande }\end{array}$ & $\begin{array}{l}\text { Manihot esculenter (yuca } \\
\text { amarga): } M . \text { utilissima } \\
\text { (yuca brava); M. aipi (yuca } \\
\text { dulce) }\end{array}$ & $\begin{array}{l}\text { Descripciones: mónade, } \\
\text { grande (145-150 um), apolar- } \\
\text { radiosimétrico, esférico, } \\
\text { pantoporado, exina pilada } \\
\text { exibindo padrón crotonoide. } \\
\text { Comentarios: scgún } \\
\text { Nowicke (1994), los géneros } \\
\text { Manihot y Cnidoscolus } \\
\text { (Tribo Manihoteae) son } \\
\text { aperturados mientras el género } \\
\text { Croton (Tribo Crotoneae) es } \\
\text { inaperturado. Referencias: } \\
\text { Bush y Weng (2007); Vieira et } \\
\text { al. (2012) }\end{array}$ & $\begin{array}{l}\text { alimentício. La yuca sigue sendo la planta consumida } \\
\text { por las poblacioncs indígenas cn territorio brasileño, } \\
\text { presente en la cultura de huertos caseros. El cultivo } \\
\text { (coivara) y el manejo (farinhadas) del tubérculo está } \\
\text { claramente presente en la cultura indígena de diversas } \\
\text { ctnias antiguas y modcrnas, dentrc cllas la Tremembé y } \\
\text { Tapeba de Ceará (NE de Brasil) y Kaingang-Xapecó S } \\
\text { de Brasil). Referencias: Friekel (1959); Amoroso y } \\
\text { Geli (1988); Porto Alegre (2000) }\end{array}$ \\
\hline $\begin{array}{l}\text { Microgrammci } \\
\text { (Polypodiaccac) } \\
\text { (Fig. 9) }\end{array}$ & $\begin{array}{l}\text { UE03 - vasija } \\
\text { pequeña globular }\end{array}$ & $\begin{array}{l}\text { Microgrimma vaccinifolia } \\
\text { (salambaia); Microgramma } \\
\text { sp. (sordinha) }\end{array}$ & $\begin{array}{l}\text { Descripción: mónade, espora } \\
\text { trilctc, bilatcral, medio ( } 36 \times 29 \\
\text { um), exoporium psilado y } \\
\text { perina reticulada. } \\
\text { Referencias: Roubik y } \\
\text { Moreno (1991); Frcitas et al. } \\
(2015)\end{array}$ & $\begin{array}{l}\text { medicinal y ritual (místico). Planta usada en los baños } \\
\text { rituales de pucblos de la ctnia Xucuri-Ororobá de } \\
\text { Pernambuco NE de Brasil), juntamente con Asplenium } \\
\text { formosum (avenca-mirim). Referencias: Silva y } \\
\text { Andrade }(2002,2004)\end{array}$ \\
\hline $\begin{array}{l}\text { Polypodium } \\
\text { (Polypodiaceae) } \\
\text { (Fig. 9) }\end{array}$ & $\begin{array}{l}\text { UE03 - vasija } \\
\text { pequeña globular }\end{array}$ & $\begin{array}{l}\text { Polypodium decumanum } \\
\text { (guaribinha; grão-de- } \\
\text { guariba); Polvpodium spp. } \\
\text { (samambaia-do-mato u } \\
\text { calaguala) }\end{array}$ & $\begin{array}{l}\text { Descripción: mónade, espora } \\
\text { trilete, bilateral, medio ( } 42 \times 30 \\
\text { um), cxoporium verrucado. } \\
\text { Referencias: Roubik y } \\
\text { Moreno (1991); Freitas y } \\
\text { Carvalho (2012); Freitas et al. } \\
\text { (2015) }\end{array}$ & $\begin{array}{l}\text { medicinal y ritual (mistico). Usado como jarabe para la } \\
\text { tos de guariba (o coqueluche), según la cultura de los } \\
\text { indios Palikur do la Guayana Francesa. Referencias: } \\
\text { Looser y Rodríguez (2004); Amoroso y Geli (1988) }\end{array}$ \\
\hline
\end{tabular}

Fig. 15 (pág. anterior y ésta). Datos morfológicos y etnobotánicos del polen y esporas de plantas útiles. 


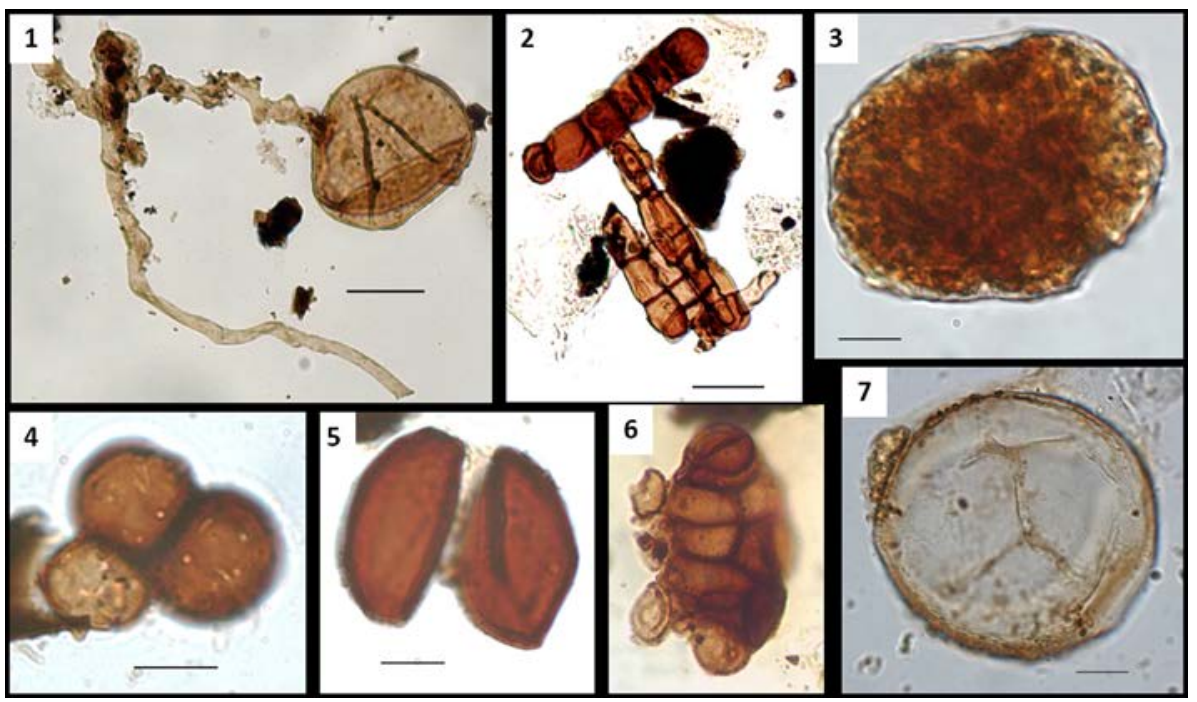

Fig. 16. Microfotografías de los tipos no polínicos recuperados de los sedimentos: 1. Glomeromycota (200x). 2. Tipo Meliola (1000x).3. Botryococcus (1000x). 4. Tricellaesporonites $(1000 x)$. 5. Tipo Xylariaceae (1000x). 6. cf. Acrodyctis (1000x). 7. Anthoceros (1000x).

\section{EL ESPECTRO POLÍNICO DE LOS SEDIMENTOS}

Las muestras de sedimentos analizados son consideradas muestras-control, o sea, son un reflejo de la lluvia polínica u otros procesos relacionados al post-uso y entierro de esos recipientes cerámicos (Arendt 2004).

En los sedimentos de la unidad arqueológica UE03 fue identificado el polen de palmeras (tipo Arecaceae- $0,8 \%$ ), vegetación arbustivo-arbórea (cf. Cactaceae-0,4\%, cf. Maytenus-0,6\%, Fabaceae-Mimosoideae-0,6\%, tipo Malvaceae- $0,8 \%$ y tipo Moraceae-Urticaceae- $1,6 \%$ ) así como hierbas (tipo Poaceae-0,4\% y tipo Gomphre$n a-1,2 \%$ ), plantas cultivadas (tipo Ipomoea-0,6\%, tipo Manihot-0,8\% y tipo Gossypium-0,8\%), granos indeterminables-7,9\%, esporas de pteridófitos (Esporas monolete-3,3\%, Acrostichum- $0.4 \%$, Asplenium-0,4\%, cf. Azolla-0,4\%, Blechnum-0,8\%, cf. Danaea-0,8\%, tipo Polypodiaceae- $4,1 \%$ y Selaginella-3\%) y microhongos (cf. Acrodictys-0,8\%, tipo Alternaria-5,4\%, tipo Curvularia-1,2\%, tipo Puccina-1,6\%, tipo EV1-001-0,4\%, Gelasinospora-3\%, Glomeromycota-6,2\%, tipo Meliola-0,4\%, tipo Sordariaceae-15,4\%, cf. Spegazzinia-0,8\%, Tricellaesporonites-1,6\% y tipo Xylariaceae-1,2\%) (figs. 7-8).

Entre los palinomorfos identificados en la unidad arqueológica UE011, fue registrado el polen de vegetación arbustivo-arbórea (Podocarpus-1,2\%, tipo Asteraceae- $0,8 \%$, cf. Euphorbiaceae- $0,4 \%$, cf. Copaifera- $0,4 \%$

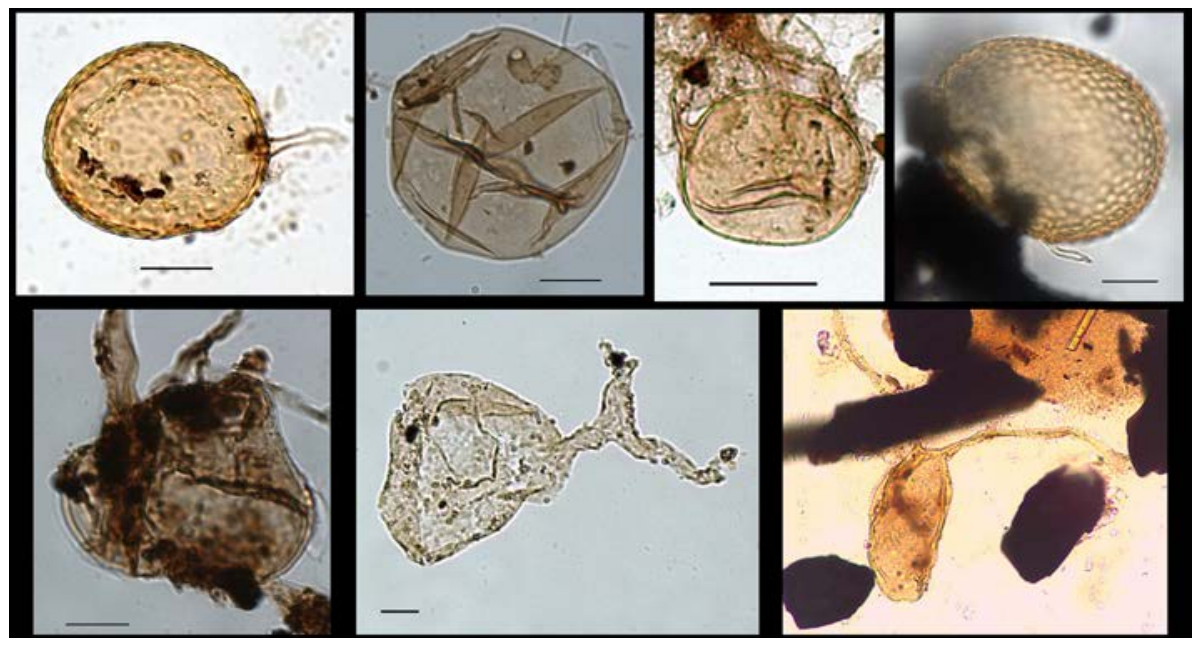

Fig. 17. Diversidad de hongos Glomeromycota identificados en contexto arqueológico. 
y tipo Malvaceae-1,6\%), arbustivo-herbácea (Passiflora- $0,4 \%$, tipo Poaceae- $5,4 \%$, tipo Amaranthaceae-Chenopodiaceae- $0,8 \%$, tipo Gomphrena-2,1\% y cf. Rubiaceae-1,6\%), plantas cultivadas (tipo Ipomoea-1,2\%, tipo Gossypium-1,2\% y tipo Cucurbita-2,1\%), granos indeterminables-7,9\%, esporas de briófitos (sensu lato) (Anthoceros-0,4\%), esporas de pteridofitos (Espora monolete-4,5\%, Acrostichum-0,8\%, cf. Anemia-0,4\%, cf. Azolla-0,4\%, Blechnum-2,1\%, tipo Polypodiaceae-7,1\% y Selaginella-1,2\%), microalgas dulceacuícolas (Botryococcus-3,7\%) y microhongos (cf. Acrodictys- $0,8 \%$, tipo Alternaria-6,2\%, tipo Puccina-10\%, Gelasinospora-0,8\%, Glomeromycota-15\%, tipo Meliola-0,4\%, Microthyrium- $0,4 \%$, tipo Cercophora-0,4\%, tipo Sordariaceae-13,3\%, cf. Spegazzinia-0,8\%, Tricellaesporonites-1,6\% y tipo Xylariaceae-1,2\%) (figs. 7-8).

En la UE03, se nota mayor frecuencia de los taxones microhongos patógenos de plantas cultivadas $(16,2 \%)$ (tipo Alternaria-6,2\% y tipo Puccinia-10\%), coprófilos (14,5\%) (Gelasinospora-0,8\%, tipo Cercophora-0,4\%, tipo Sordariaceae-13,3\%) además de esporas de pteridófitos (14\%) (tipo Polypodiaceae-4,1\%, Selaginella-3\% y Blechnum-0,8\%). Mientras en la UE011, los taxones herbáceos (15\%), coprófilos (18\%) (Gelasinospora-3\% y tipo Sordariaceae-15\%), Glomeromycota (15\%) y esporas de pteridófitos (17\%) (tipo Polypodiaceae-7,1\%, Blechnum-2,1\% y Selaginella-1,2\%) son los más representativos (figs. 7-8).

\section{EL CONTEXTO PALEOFLORÍSTICO Y PALEOECO- LÓGICO}

El espectro polínico de los sedimentos revela la presencia de taxones arbustivo-arbóreos y arbustivo-herbáceos característicos de bosques húmedos, deciduos o caducifolios y vegetación xerófita, frecuentes en el Bioma Caatinga (Alcoforado-Filho et al. 2003) (figs. 5 y 7). En los Brejos de altitude, en la transición entre bosque húmedo y xerófito, se presenta una alta diversidad arbustivoarbórea (Euphorbiaceae, Fabaceae sub-familias Mimosoideae y Caesalpinioideae, Cactaceae, Anacardiaceae y Asteraceae) (Alcoforado-Filho et al. 2003). En un estudio florístico en ambientes montañosos de la Caatinga, Ferraz et al. (1998) registran taxones leñosos adaptados a ambientes más húmedos (1100-900 m s.n.m) (Asteraceae, Maytenus, Moraceae, Urticaceae y Ipomoea) y más secos (700-500 m s.n.m) (Manihot y Malvaceae). Sin embargo, Mimosoideae y Cactaceae posee una amplia distribución, entre 1100-500 m s.n.m. Estos taxones poseen mayor riqueza entre las fitofisionomías presentes en este Bioma. Los tipos arbustivo-arbóreos registrados (Dalechampia, tipo Malvaceae y tipo Asteraceae) también se presentan en zonas más secas como la Depressão Sertaneja (Alcoforado-Filho et al. 2003). La diversidad de tipos polínicos arbustivo-arbóreos (Podocarpus, cf. Copaifera, tipo Arecacae, cf. Cactaceae, Euphorbiaceae, Astronium, cf. Anacardium, cf. Dalechampia, FabaceaeMimosoideae y tipo Malvaceae) (fig. 7) puede ser explicado por el contexto geográfico y microclimático de la Serra de Baturité. Las especies botánicas presentes en la vertiente de barlovento reflejan vegetación húmeda (atlántica y amazónica) y en la vertiente sotavento, destacan los tipos estacionales y matorral xerofítico. La riqueza y la diversidad actual de las fabáceas en Baturité está representada por Mimosa e Inga, presentes en bosques húmedos y xerofíticos (Lima y Mansano 2011). Copaifera y Podocarpus también fueron registradas en bosques húmedos (Ledru et al. 2006; Lima y Mansano 2011) (fig. 7). El polen de palmera (tipo Arecaceae) y árboles de bosques secundarios (tipo Moracae-Urticaceae) sugieren la influencia humana en el paisaje, reflejando el establecimiento de los grupos humanos prehistóricos en la región (Nascimento et al. 2009). Los valores de $\delta{ }^{13} \mathrm{C}(-25,1 \%$ ) procedente del carbón datado de la UE011 (fig. 4), indican plantas arbustivo-arbóreas de metabolismo $\mathrm{C}_{3}$, de caráter xerófito, como ejemplo de los paleosuelos ( 3200 BP) de la FLONA de la Chapada do Araripe (Pernambuco) (Pessenda et al. 2010). Las plantas herbáceas nitrófilas anuales registradas, tipo Amaranthaceae-Chenopodiaceae (fig. 7), indican actividades antrópicas intensivas, como los cultivos, causando profundas alteraciones químicas en los suelos, destruyendo la vegetación original y favoreciendo la dispersión de las semillas de plantas cultivadas (Rivas-Martínez 1977). Las esporas de pteridófitos más frecuentes (Blechnum, Polypodium y Selaginella) poseen hábito ecológico herbáceo, terrícola o epífito, viviendo en los bosques húmedos de altitud y en formaciones vegetales secundarias o antropizadas (Freitas et al. 2015) (fig. 7).

También se registran algas como Botryococcus y altos porcentajes de microhongos (UE03=29\% y UE011=37\%), indicadores de ambientes húmedos, naturales y antrópicos (figs. 7-8). Los hongos micorrícicos arbusculares (HMAs) Glomeromycota viven en asociación simbiótica con la mayoría de las plantas terrestres (Wang y Liu 2006) y con plantas invasoras de suelos antropogénicos (comun. pers., Dr. Orivaldo Saggin-Júnior, 
Aline Gonçalves de Freitas, José Sebastián Carrión García, Santiago Fernández Jiménez, Igor Pedroza, Caroline Fernandes Caromano, Leandro Mathews Cascón, Gina Faraco Bianchint, Sergio Francisco Serafim Monteiro da Silva, Neuvania Curty Ghetti, Claudia Alves de Oliveira

\begin{tabular}{|c|c|c|c|c|}
\hline \begin{tabular}{|l} 
TIPOS NO \\
POLÍNICOS \\
\end{tabular} & OCURRENCIA & \begin{tabular}{|l|} 
AFINIDAD \\
BOTÁNICA
\end{tabular} & DATOS MORFOLÓGICOS & DATOS ECOLÓGICOS \\
\hline $\begin{array}{l}\text { tipo Alternaria } \\
\text { (fig. 5) }\end{array}$ & $\begin{array}{l}\text { UE011 - vasija } \\
\text { grande piriforme }\end{array}$ & $\begin{array}{l}\text { Alternaria sp:; } A \text {. } \\
\text { macrospora; } A \text {. } \\
\text { alternata }\end{array}$ & $\begin{array}{l}\text { Descripción: conidia obclavado ( } 45 \times 20 \text { um) } \\
\text { disminuiendo gradualmente hasta la punta, con } \\
\text { tabiques transversales longitudinalmente. } \\
\text { Referencias: Van Geel } \text { et al. (2011) }\end{array}$ & $\begin{array}{l}\text { Hongo patógeno de las raíces del } \\
\text { algodón (Gossypium spp.). } \\
\text { Referencias: Árias y Tappari (2004). }\end{array}$ \\
\hline tipo Cirvularia & $\begin{array}{l}\text { UE011 - vasija } \\
\text { grande piriforme }\end{array}$ & Curvularia sp. & $\begin{array}{l}\text { Descripción: conidios curvados con tres o más } \\
\text { tabiques transversales ( } 30 \times 17 \text { um), células } \\
\text { centrales más oscuras que las células finales. } \\
\text { Referencias: Van Geel et al. (2011) }\end{array}$ & $\begin{array}{l}\text { Ambientes acuáticos mesotróficos; } \\
\text { Curvularia sp. es patógeno del maiz, } \\
\text { camote, ñame, pimienta, chile, arroz, } \\
\text { trigo, césped común y jengibre. } \\
\text { Referencias: Gelorini et al. (2011) }\end{array}$ \\
\hline $\begin{array}{l}\text { tipo Puccinia } \\
\text { (figs. 4-5) }\end{array}$ & $\begin{array}{l}\text { todas las ceramicas } \\
\text { analizadas }\end{array}$ & Puccinia sorghi & $\begin{array}{l}\text { Descripción: teleutospora dicelado, uniseptado } \\
\text { (43x25 um), constricto en el septo, pared } \\
\text { relativamente espesa hialina, } 3 \text { um, con poros } \\
\text { apicales ( } 2 \text { um). Referencias: Van Geel } \text { et al. } \\
\text { (1981) }\end{array}$ & $\begin{array}{l}\text { Puccinia spp. (la roja comúm) es hongo } \\
\text { patógeno del maíz y de otras gramíneas } \\
\text { naturales o cultivadas. Referencias: } \\
\text { Peixoto Júnior (2011) }\end{array}$ \\
\hline \begin{tabular}{|l|} 
Gelasinospora \\
(figs. 4-5)
\end{tabular} & $\begin{array}{l}\text { todas las ceramicas } \\
\text { analizadas }\end{array}$ & $\begin{array}{l}\text { Gelasinospora } \\
\text { sp. }\end{array}$ & $\begin{array}{l}\text { Descripción: ascospora elíptico, no septado } \\
(35 x 25 \text { um), superficie marrón ornamentada con } \\
\text { alvéolos hialinos. Referencias: Van Geel y } \\
\text { Aptroot (2006); Van Geel et al. (2011) }\end{array}$ & $\begin{array}{l}\text { Ocurre principalmente en los } \\
\text { excrementos, pero también se producen } \\
\text { en la madera carbonizada. Su presencia } \\
\text { suele indicar sucesivas quemas tanto } \\
\text { para cultivos cuanto para la caza. } \\
\text { Referéncias: Gelorini et al. (2011) }\end{array}$ \\
\hline $\begin{array}{l}\text { Glomeromycota } \\
\text { (figs. 16-17) }\end{array}$ & $\begin{array}{l}\text { todas las ceramicas } \\
\text { analizadas }\end{array}$ & $\begin{array}{l}\text { Glomus spp.; } \\
\text { Gigaspora spp.; } \\
\text { Acaulospora } \\
\text { spp. }\end{array}$ & $\begin{array}{l}\text { Descripción: clamidospora globoso (tamaño } \\
\text { variable) con exclusión de la junción de las } \\
\text { hifas. Referencias: Van Geel et al. (2011) }\end{array}$ & $\begin{array}{l}\text { Hongos endomicorrízicos arbusculares } \\
\text { asociados a las raices de las plantas de } \\
\text { bosques tropicales húmedos; presente } \\
\text { en monocultivos (caña de azúcar, } \\
\text { patatas dulces y maíz) y en suelos que } \\
\text { sufrieron reelaboración o remoción. } \\
\text { Referencias: Gelorini et al. (2011); } \\
\text { Van Geel et al. (2011) }\end{array}$ \\
\hline $\begin{array}{l}\text { tipo Sordariaceae } \\
\text { (figs. 4-5) }\end{array}$ & $\begin{array}{l}\text { todas las ceramicas } \\
\text { analizadas }\end{array}$ & Sordaria sp. & $\begin{array}{l}\text { Descripción: ascospora elíptico (20x } 10) \text {, con } \\
\text { poro apical y otro poro más pequeño en el otro } \\
\text { extremo. Referencias: Van Geel et al. (2011) }\end{array}$ & $\begin{array}{l}\text { Sordaria es coprófilo de herbivoros y } \\
\text { de humanos. Normalmente ocurre en } \\
\text { asociación a ascosporas de otros } \\
\text { Ascomycetes coprófilos. Común en los } \\
\text { yacimientos arqueológicos europeos. } \\
\text { Referencias: Cugny et al. (2011); } \\
\text { Gelorini et al. (2011) }\end{array}$ \\
\hline $\begin{array}{l}\text { cf. Ustilago } \\
\text { maydis (figs. 4-5) }\end{array}$ & $\begin{array}{l}\text { UE011 - vasija } \\
\text { grande piriforme }\end{array}$ & Ustilago maydis & $\begin{array}{l}\text { Descripción: espora globoso }(20-25 \text { um), } \\
\text { suavemente irregular, castanho-calo, con pared } \\
\text { gruesa, reticulada-verrucada. Referencias: Van } \\
\text { Geel et al. (2011) }\end{array}$ & $\begin{array}{l}\text { Importante hongo patógeno del maíz } \\
\text { (Zea mays). Referencias: Da Ponte } \\
\text { (1967) }\end{array}$ \\
\hline
\end{tabular}

Fig. 18. Microhongos relacionados a actividades humanas.

EMBRAPA (Empresa Brasileira de Pesquisa Agropecuária) - Agrobiologia, Se observa una gran disparidad entre los Glomeromycota (15\%) y las amarantáceas (tipo Amaranthaceae-Chenopodiaceae-0,8\% y tipo Gomphrena-2,1\%) registradas en los sedimentos de la UE011 (fig. 7). Es sabido, que las amarantáceas son plantas no formadoras de micorrizas de Glomeromycota (Brundrett 2008), sin embargo, algunos géneros las producen, en desacuerdo con los tipos aquí identificados. Esa disparidad puede señalar influencia humana en la selección de esos tipos de plantas, como se discute en este trabajo más adelante. Por otra parte, es conocida las relaciones entre las gramíneas (tipo Poaceae-5,4\%) y las esporulaciones de los hongos Glomeromycota (Burrows y Pfleger 2002), reconocida en los sedimentos de la UE011 (figs. 7-8). Curiosamente, hubo ocurrencia notoria de Glomeromycota en la vasija cerámica pequeña globular de la UE03, en contraste a los bajos porcentajes de estos hongos en los sedimentos recogidos de su interior (6,2\%) (figs. 7-8). De la misma forma, en los suelos de la UE011 se registran altos porcentajes de Glomeromycota (15\%) en contraste a los fragmentos cerámicos de esa misma unidad (figs. 7-8). Esto puede estar relacionado con las condiciones de preservación de las esporas en el 


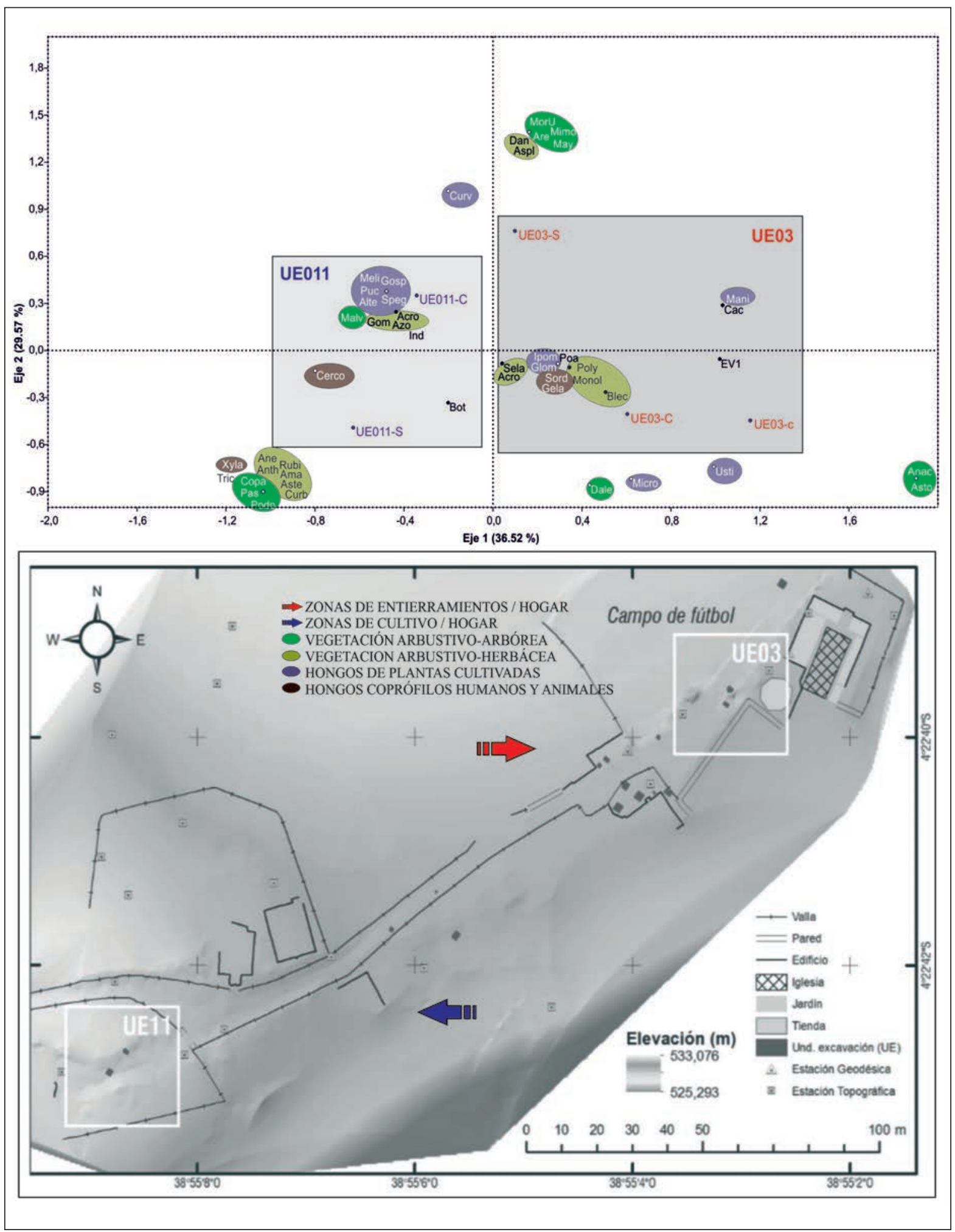

Fig. 19. Análisis de Correspondencia (CA) indicando la distribución políni/ca en las unidades arqueológicas excavadas. 
Aline Gonçalves de Freitas, José Sebastián Carrión García, Santiago Fernández Jiménez, Igor Pedroza, Caroline Fernandes Caromano, Leandro Mathews Cascón, Gina Faraco Bianchini, Sergio Francisco Serafim Monteiro da Silva, Neuvania Curty Ghetti, Claudia Alves de Oliveira

suelo, o una posible contaminación de esporas modernas debido a una mezcla temporal, o sencillamente hubo penetración de sus finas hifas en poros del suelo hasta alcanzar los nutrientes o agua interna en la cerámica, y allí entonces se produjo la esporulación. Además, estos hongos producen una sustancia altamente recalcitrante en los suelos, la glomalina (comun. pers., Dr. Orivaldo SagginJúnior, EMBRAPA (Empresa Brasileira de Pesquisa Agropecuária) - Agrobiologia, que será analizada en estudios futuros.

\section{CONSIDERACIONES FINALES Y PERSPECTIVAS FUTURAS}

En base a los hallazgos arqueopalinológicos, podemos inferir algunos aspectos paleoecológicos y paleoetnobotánicos sobre el Yacimiento Evaristo I:

(1) Los porcentajes polínicos de los sedimentos indican un paleoambiente dominado por bosques húmedos, deciduos o caducifolios y xerófitos frecuentes en el Bioma Caatinga, por la presencia de taxones arbustivo-arbóreos (Podocarpus, Asteraceae, cf. Cactaceae, cf. Maytenus, cf. Dalechampia, cf. Copaifera, Fabaceae-Mimosoideae, tipo Malvaceae, tipo Moraceae-Urticaceae) y arbustivo-herbáceos (tipo Poaceae, tipo Amaranthaceae-Chenopodiaceae, tipo Gomphrena y cf. Rubiaceae). También hubo registro de plantas cultivadas (como las calabazas - tipo Cucurbita).

(2) Los análisis polínicos de los fragmentos cerámicos nos permiten inferir sobre la dieta de los grupos alfareros prehistóricos. Estos datos evidencian una alimentación de origen vegetal diversificada por parte de las poblaciones alfareras, basada en el consumo de tubérculos (yuca - tipo Manihot, camote - tipo Ipomoea), maíz (Zea mays) y otras gramíneas, además de plantas fructíferas (palmeras - tipo Arecaceae, caju-cf. Anacardium y maracujá- Passiflora).

(3) En relación al paisaje construido, notase la presencia de polen de plantas naturales y cultivadas como fuente de recursos (polen económico), presente tanto en los suelos como en los fragmentos cerámicos analizados. El registro de microhongos patógenos asociados a plantas como el caju (Anacardium occidentale), el maíz (Zea mays), la caña de azúcar (Saccharum officinarum) y el camote (Ipomoea batatas) refuerzan la hipótesis de horticultura en virtud a la durabilidad de los asentamientos de las poblaciones de alfareros prehistóricos en la región.
(4) Aunque todavía no es posible establecer las filiaciones a las tradiciones alfareras regionales brasileñas, podemos inferir sobre la utilización de los artefactos cerámicos analizados. Las vasijas servían probablemente para al almacenamiento y preparación de alimentos, para la recogida del agua y para destino funerario. El espectro polínico del conjunto de vasijas representa un contexto funerario y doméstico, destacando las actividades agrícolas.

(5) La presencia y altas frecuencias de los microhongos coprófilos (Gelasinospora y tipo Sordariaceae) de humanos y otros animales silvestres o domésticos, en las dos unidades arqueológicas analizadas, son indicativas del sedentarismo, con probable aumento poblacional entre los alfareros. Los datos polínicos y dataciones sugieren que estos grupos tuvieron tiempo suficiente para una organización social y subsistencia múltiple, basada en la horticultura, la caza y recolección de frutos, semillas y madera, tanto en usos domésticos como en sus rituales funerarios.

(6) Los datos polínicos de los sedimentos son relevantes para caracterizar la vegetación del entorno del área arqueológica simultáneo u contemporáneo al entierro de las vasijas, puesto que todavía no disponemos de dataciones de los sedimentos. Sin embargo, todavía no son definitivos a efectos de reconstrucción palaeoambiental ya que el suelo del yacimiento Evaristo I se encuentra erosionado debido a factores antrópicos y naturales, por el continuum agrícola de los últimos tres siglos, sobre todo por los cultivos de café y plátano, con exposición y eventuales dispersiones aleatorias de vestigios arqueológicos. Mientras tanto, la recolección sistemática de las muestras en las áreas interiores de las vasijas o en el interior de la propia masa cerámica quemada, minimizan el factor de contaminación e indican cierta disparidad en los taxones identificados en este trabajo. En este contexto, se pueden asumir las siguientes hipótesis para los sedimentos analizados: (a) que estos taxones fueron conservados dentro de las vasijas intactos por su cierre (o tapa), preservándolos y considerándose de la misma época que los enterramientos; (b) o bien, que estos sufrieron procesos post-deposicionales naturales (i.e., lixiviación y otros procesos erosivos) o antropogénicos, posteriores al entierro de las vasijas, causando una mezcla temporal, considerándose contemporáneos a los enterramientos.

(7) Este estudio integra un proyecto mayor sobre el origen, dispersión y contexto cultural de las poblaciones alfareros-horticultoras de sierras húmedas del NE de Brasil, dirigido por la Profa. Dra. Claudia Alves de Oliveira (Departamento de Arqueologia, Universidade Federal de Pernambuco). En continuidad al presente trabajo, se 
pretende llevar a cabo: a) un muestreo de control para el conocimiento de la flora actual en el entorno del yacimiento; b) análisis polínicos estratigráficos alrededor de yacimiento y c) análisis de los artefactos cerámicos recogidos de todas las unidades arqueológicas. Además, la integración de otros indicadores arqueobotánicos (fitolitos y macrocarbones) y estudio estratigráfico, geomorfológico y geocronológico del yacimiento Evaristo I. Estas informaciones nos permitirán valorar con más criterio el paleopaisaje durante el proceso de ocupación, el tiempo de permanencia, estrategias de subsistencia, modo de vida y muerte de los grupos alfareros prehistóricos.

Aline Gonçalves de Freitas José Sebastián Carrión García Santiago FernándeZ JiméneZ Grupo de Investigación E005-11 - Paleoecología, Paleoantropologia y Tecnología del Cuaternário Departamento de Biología Vegetal (Botánica) Universidad de Murcia aline.goncalves@um.es carrion@um.es santiago@um.es

IgOR Pedroza Programa de Pós-Graduação em Arqueologia Universidade Federal de Pernambuco igorpedroza@gmail.com

Caroline Fernandes Caromano Leandro Mathews Cascón Museu de Arqueologia e Etnologia Laboratório de Estudos Humanos Evolutivos Universidade de São Paulo carolcaromano@gmail.com

Gina FARACO BiANCHINI Laboratório Casa de Pedra - Departamento de Arqueologia Museu Nacional - Universidade Federal do Rio de Janeiro ginabianchini@ufrj.br

Sergio Francisco Serafim Monteiro da Silva Neuvania Curty Ghetti Claudia Alves de Oliveira Departamento de Arqueologia Universidade Federal de Pernambuco sergioarqueologiaforense@gmail.com ghettister@gmail.com olivas@hotlink.com.br

\section{AGRADECIMIENTOS}

Los autores agradecen al Instituto do Patrimônio Histórico e Artístico Nacional (IPHAN-CE), Empresa Arqueosocio, Comunidade da Serra do Evaristo, Ministério da Educação do Brasil (CAPES/BEX-11757/13-2), CNPq, Emília Arnaldo por la colaboración en las intervenciones arqueológicas, Lucila Borges y Marcelo Silva por proveer el procesamiento palinológico. Marcelo Carvalho por la infraestructura en las microfotografías. Vania GonçalvesEsteves y Claudia Barbieri por las revisiones palinotaxonómicas. Orivaldo Saggin-Júnior por las identificaciones de los hongos Glomeromycota y María del Mar Gutiérrez por la lectura crítica y valiosas sugerencias. Los revisores anónimos por las contribuciones que mejoran en gran medida el manuscrito.

\section{BIBLIOGRAFÍA}

AB'SÁBER, A. (1994): No domínio das catingas, Caatingas: Sertão e Sertanejos (S. Monteiro, Kaz, coords.), Rio de Janeiro, 47-55.

ALBUQUERQUE, M.; LUCENA, V. (1991): Agricultura Tropical Pré-Histórica (um sistema de floresta úmida ou que integra o semi-árido?), Ciência e Trópico 19 (1), 7-33.

ALCOFORADO-FILHO, F. G.; SAMPAIO, E. V. S. B.; RODAL, M. J. N. (2003): Florística e fitossociologia de um remanescente de vegetação caducifólia espinhosa em Caruaru, Pernambuco, Acta Botanica Brasilica 17, 287-303. DOI: http://dx.doi.org/10.1590/s0102-33062003000200011

AMOROSO, M. C. M.; GELI, A. (1988): Uso de plantas medicinais por caboclos do Baixo Amazonas. Barcarena, PA, Brasil, Boletim do Museu Paraense Emilio Goeldi 4 (1), 48-131.

ARCHILLA, S. (2009): Arqueobotánica en Colombia y su aplicación al estudio de patrones alimenticios y explotación de recursos vegetales en el pasado, La alimentación en la América precolombiana y colonial: una aproximación interdisciplinaria, Trebalis D'Etnoarqueologia 7 (A. Capparelli et al.), 55-66.

ARENDT, N. (2004): Artifacts washes <http://www.geo.arizona. edu/palynology/arch_pal_origagric.html $>$ (Consulta 15-V2015).

ARIAS, G.; TAPPARI, E. (2004): Guía de Identificación de plagas $e$ insectos benéficos en cultivo de algodón EEA INTA Sáenz Peña-Proyecto "Manejo Integrado del Picudo del Algodonero en Argentina, Brasil y Paraguay ICAC/04".

BAUERMANN, S. G.; EVALDT, A. C. P.; ZACHIN, J. R.; BORDIGNON, S. A. L. (2010): Diferenciação polinica de $B u$ tia, Euterpe, Geonoma, Syagrus e Thritrinax e implicações paleoecológicas de Arecaceae para o Rio Grande do Sul, Iheringia 65 (1), 35-46.

BEHLING, H.; ARZ, H. W.; PATZOLD, J.; WEFER, G. (2000): Late Quaternary vegetational and climate dynamics in northeastern Brazil, inferences from marine core GeoB 31041, Quaternary Science Reviews 19, 981-994. DOI: http://dx.doi.org/10.1016/S0277-3791(99)00046-3

BIANCHINI, G. F.; GASPAR, M. D.; DEBLASIS, P.; SCHEELYBERT, R. (2011): Processos de formação do sambaqui Jabuticabeira-II: interpretações através da análise estratigráfica de vestígios vegetais carbonizados, Revista do $\mathrm{Mu}$ seu de Arqueologia e Etnologia 21, 51-69. 
Aline Gonçalves de Freitas, José Sebastián Carrión García, Santiago Fernández Jiménez, Igor Pedroza, Caroline Fernandes Caromano, Leandro Mathews Cascón, Gina Faraco Bianchini, Sergio Francisco Serafim Monteiro da Silva, Neuvania Curty Ghetti, Claudia Alves de Oliveira

BISOGNIN, D. A. (2002): Origin and evolution of cultivated cucurbits (Origem e evolução das cucurbitáceas cultivadas), Ciência Rural 32 (4), 715-723. DOI: http://dx.doi.org/10.1590/s0103-84782002000400028

BOSCOLO, O.; SENNA VALLE, L. (2008): Plantas de uso medicinal em Quissamã, Rio de Janeiro, Brasil, Iheringia 63 (2), 263-277.

BROCHADO, J. P. P. (1977): Alimentação na Floresta Tropical, Porto Alegre.

BROCHADO, J. P. P. (1991): A tradição cerámica Tupi-Guarani na América do Sul, Clio Série Arqueológica 3, 47-60.

BRUNDRETT, M. C. (2008): Micorrhizal associations: The web resource. Section 6. Nomycorrhizal plants <http://mycorrhizas.info/nmplants.html> (Consulta 10-V-2015).

BRYANT, V. M.; HALL, S. A. (1993): Archaeological palynology in the United States: a critique, American Antiquity 58 (2), 277-286. DOI: http://dx.doi.org/10.2307/281970

BURJACHS, F.; LÓPEZ-SÁEZ, J. A.; IRIARTE, M. J. (2000): Metología Arqueopalinológica, En la recogida de muestras en arqueobotánica: objetivos y propuestas metodológicas. La gestión de los recursos vegetales y la transformación del paleopaisaje en el Mediterráneo occidental, Encuentro del grupo de trabajo de arqueobotánica de la Península Ibérica, Barcelona/Bellaterra, 9-16.

BURROWS, R. L.; PFLEGER, F. L. (2002): Arbuscular mycorrhizal fungi respond to increasing plant diversity, Canadian Journal of Botany 80 (2), 120-130. DOI: http://dx.doi.org/10.1139/b01-138

BUSH, M.; WENG, C. (2007): Introducing new (freeware) tool for palynology, Journal of Biogeography 34, 377-380. DOI: http://dx.doi.org/10.1111/j.1365-2699.2006.01645.x

CARRIÓN, J. S.; MUNUERA, M. (1997): Upper Pleistocene paleoenvironmental change in eastern Spain: new pollenanalytical data from Cova Beneito (Alicante). Palaeogeography, Palaeoclimatology, Palaeoecology 128, 287-299. DOI: http://dx.doi.org/10.1016/s0031-0182(96)00062-4

CARRIÓN, J. S.; MUNUERA, M. G.; NAVARRO, C. C.; SÁEZ, F. S. (2000): Paleoclimas y historia de la vegetación cuaternaria en España a través del análisis polínico. Viejas falacias y nuevos paradigmas, Complutum 1, 115-142.

CARRIÓN, J. S.; GIL, C.; RODRÍGUEZ, E.; FUENTES, N.; GARCÍA-ANTÓN, M.; ARRIBAS, A. (2005): Palynology of badger coprolites from Central Spain, Palaeogeography, Palaeoclimatology, Paleaeoecology 226, 259-271. DOI: http://dx.doi.org/10.1016/j.palaeo.2005.05.016

CARRIÓN, J. S.; FERNÁNDEZ, S.; GONZÁLEZ-SAMPÉRIZ, P.; LEROY, S. A. G.; LÓPEZ-SÁEZ, J. A.; BURJACHS, F.; GILROMERA, G.; RODRÍGUEZ-SÁNCHEZ, E.; GARCÍAANTÓN, M.; GIL-GARCÍA, M. J.; PARRA, I.; SANTOS, L.; LÓPEZ-GARCÍA, P.; YLL, E. I.; DUPRÉ, M. (2009): Quaternary pollen analysis in the Iberian Peninsula: the value of negative results, Internet Archaeology<http:/intarch.ac.uk/journal/ issue25/carrion_index.html> (Consulta 18-I-2014). DOI: http://dx.doi.org/10.11141/ia.25.5
CHAVES, S. A. M. (2002): História das Caatingas, a reconstituição paleoambiental da Região Arqueológica do Parque Nacional da Serra da Capivara, através da palinologia, Revista da Fundação Museu do Homem Americano, São Raimundo Nonato (FUNDHAM) 2 (1).

CORRÊA-DA-SILVA, B. C. (2010): Etnolinguística e etno-história Tupí: desfragmentando o olhar, Rev. Est. Ling, Belo Horizonte 18 (1), 61-86.

DOI: http://dx.doi.org/10.17851/2237-2083.18.1.61-86

COUTINHO, D. F.; TRAVASSO, L. M. A.; AMARAL, F. M. M. (2002): Estudo etnobotánico de plantas medicinais utilizadas em comunidades indígenas no Estado do Maranhão Brasil, Visão Acadêmica 3 (1), 7-12. DOI: http://dx.doi.org/10.5380/acd.v3i1.493

CRUZ JUNIOR, F. W.; VUILLE, M.; BURNS, S. J.; WANG, X.; CHANG, H.; WERNER, M.; EDWARDS, R. L.; KARMANN, I.; AULER, A.; NGUYEN, H. (2009): Orbitally driven east-west anti-phasing of South American precipitation, Nature Geosciences 2, 210-214.

DOI: http://dx.doi.org/10.1038/ngeo444

CUGNY, C.; MAZIER, F.; GALOP, D. (2010): Modern and fossil non-pollen palynomorphs from the Basque mountains (western Pyrenees, France): the use of coprophilous fungi to reconstruct pastoral activity, Vegatation History and Aracheobotany 19, 391-408.

DOI: http://dx.doi.org/10.1007/s00334-010-0242-6

DA PONTE, J. (1967): Resistencia de las Clamidosporas de Ustilago Maydis (DC.) Cda. A las altas Temperaturas. Sydowia 21, 159-162.

DE OLIVEIRA, P. E.; BARRETO, A. M. F.; SUGUIO, K. (1999): Late Pleistocene/Holocene climatic and vegetational history of the Brazilian Caatinga: the fossil dunes of the middle São Francisco River, Palaeogeography, Palaeoclimatology and Palaeoecology 152 (3-4), 319-337.

DOI: http://dx.doi.org/10.1016/S0031-0182(99)00061-9

DIMBLEBY, G. W. (1985): The palynology of archaeological sites. Studies in Archaeological Science, London. DOI: http://dx.doi.org/10.1017/s0079497x00007386

ETCHEVARNE, C. (2012): O sítio de Tradição Aratu de Água Vermelha, Reserva Indígena Caramuru Paraguaçu, e suas implicações arqueológicas e etno-políticas, Cardernos de Arte e Antropologia 1 (1), 2-7.

DOI: http://dx.doi.org/10.4000/cadernosaa.721

FERRAZ, E. M. N.; RODAL, M. J. N.; SAMPAIO, E. V. S. B.; PEREIRA, R. C. A. (1998): Composição florística em trechos de vegetação de Caatinga e brejo de altitude na região do Vale do Pajeú, Pernambuco, Revista Brasileira de Botânica $21,7-15$.

FREITAS, A. G.; CARVALHO, M. A. (2012): Análise morfológica e inferências ecológicas de grãos de pólen e esporos (últimos > 8000 anos) da Lagoa da Ferradura, Armação dos Búzios, RJ, Brasil, Revista Brasileira de Paleontologia 15 (3), 300-318. DOI: http://dx.doi.org/10.4072/rbp.2012.3.06 
FREITAS, A. G.; CARVALHO, M. A.; DE TOLEDO, M. B.; MENDONÇA. C. B. F.; GONÇALVES-ESTEVES, V. (2015): Bryophyte and pteridohyte spores and other palynomorphs in quaternary marine sediments from Campos Basin, southeastern Brazil: Core BU-91-GL-05, Acta Botanica Brasilica 29 (2), 161-174.

FRIEKEL, P. (1959): Agricultura dos índios Munduruku, Boletim do Museu Paraense Emilio Goeldi 4, 1-18.

FUENTES, N.; GARCÍA-MARTÍNEZ, M; GONZÁLEZ-SAMPÉRIZ, P.; FERNÁNDEZ, S.; CARRIÓN, J. S.; ROS, M.; LÓPEZ-CAMPUZANO, M.; MEDINA, J. (2005): Degradación ecológica y cambio cultural durante los últimos cuatro mil años en el sureste ibérico semiárido, Anales de Biología 27, 69-84.

GELORINI, V.; VERBEKEN, A.; VAN GEEL, B.; COCQUYT, C.; VERSCHUREN, D. (2011): Modern no-pollen palynomorfphs from East African lake sediments, Review of $\mathrm{Pa}$ laeobotany and Palynology 164, 143-173. DOI: http://dx.doi.org/10.1016/j.revpalbo.2010.12.002

GUIDON, N.; PESSIS, A.-M. (1993): Recent discoveries on the Holocene levels of Sítio do Meio rock-shelter, Piauí, Brazil, Clio Série Arqueológica 1 (9), 77-80.

HAMMER, O.; HARPER, D. A. T.; RYAN, P. D. (2001): PAST: Paleontological Statistics Software Package for Education and Data Analysis, Palaeontologia Electronica 4 (1), 4-9.

HASTORF, C. A . (1999): Recent research in Palaeoethnobotany, Journal of Archaeological Research 7 (1), 55-103. DOI: http://dx.doi.org/10.1007/bf02446085

HAVERROTH, M. (1997): Kaingang, um estudo Etnobotânico. Uso e classificação das Plantas na Área Indígena Xapecó (oeste de SC), Master, Universidade Federal de Santa Catarina. $182 \mathrm{p}$.

HIDALGO, R.; FERNÁNDEZ, I. (1996): Contribución al estudio morfológico del polen de plantas hortícolas cultivadas en Andalucía, Lagascalia 18 (2), 151-162.

HOGG. A.; HUA, Q.; BLACKWELL, P. G.; NIU, M.; BUCK, C. E.; GUILDERSON, T. P.; HEATON, T. J.; PALMER, J. G.; REIMER, P. J.; REIMER, R. W.; TURNEY, C. S. M.; ZIMMERMAN, S. R. H. (2013): SHCal13 Southern Hemisphere calibration 0-50,000 years cal BP, Radiocarbon 55 (2), 1-15.

DOI: http://dx.doi.org/10.2458/azu_js_rc.55.16783

HOLLOWAY, R. G.; BRYANT, V. M. (1986): New directions of Palynology in Ethnobiology, Journal of Ethnobiology 6 (1), 47-65.

JAYEOLA, A. A.; OLADUNJOYE, O. R. (2012): Systematic studies in some Ipomoea Linn. species and flower morphology, Annals of West University of Timişoara, ser. Biology 15, 177-187.

JONES, G. D.; McCURRY, H. (2012): Differentiating pollen from four species of Gossypium, Palynology 36 (1), 80-85. DOI: http://dx.doi.org/10.1080/01916122.2011.619363
LEDRU M. P.; CECCANTINI, G.; GOUVEIA, S. E. M.; LOPEZ SAEZ, J.A.; PESSENDA, L. C. R.; RIBEIRO, A. S. (2006): Milenial-scale climatic and vegetation changes in a northern Cerrado (Northeast, Brazil) since the Last Glacial Maximum, Quaternary Science Reviews 25 (9-10), 1110-1126. DOI: http://dx.doi.org/10.1016/j.quascirev.2005.10.005

LIMA, J. R.; MANSANO, V. F. M. (2011): A família Leguminosae na Serra de Baturité, Ceará, uma área de Floresta Atlântica no semiárido brasileiro, Rodriguesia 62 (3), 563-613.

LIMA ROCHA, R. (2009): Particularidades de la cerámica Pintada Tupiguarani, Arqueología y Territorio 6, 39-55.

LLOBERA, J. R. (1979): As sociedades primitivas, Rio de Jaineiro, $142 \mathrm{p}$.

LOOSER, G.; RODRÍGUEZ, R. (2004): Los helechos medicinales de Chile y sus nombres vulgares, Gayana Botánica 61 (1), 1-5. DOI: http://dx.doi.org/10.4067/s0717-66432004000100001

MADALENO, I. M. (2011): Plantas da medicina popular de São Luís, Brasil, Boletim do Museu Paraense Emilio Goeldi 6 (2), 273-286.

DOI: http://dx.doi.org/10.1590/s1981-81222011000200002

MARANCA, S. (1991): Agricultores e ceramistas da área de São Raimundo Nonato, Piauí, Anais do I Simpósio de PréHistória do Nordeste1987, Recife, Revista Clio Série Arqueológica 1 (4), 95-97.

MARTIN, G. (1994): Os rituais funerários na Pré-História do Nordeste, Comunicación presentada en la VII Reunião Científica de la Sociedade de Arqueologia Brasileira-SAB, João Pessoa-PB, 1993, 1-18.

MARTIN, G. (1998): Pré-história do Nordeste do Brasil, Recife.

MENDONÇA FILHO, J. G.; CARVALHO, M. A.; MENEZES, T. R. (2002): Palinofácies, Técnicas e procedimentos de trabalho com fósseis e formas modernas comparativas (T. L. Dutra), São Leopoldo, 20-24.

MONTANI, M.C. (2012): Uso medicinal de plantas entre descendentes Huarpes en la comunidad de Lagunas del Rosario (Mendoza, Argentina), Etnobotánica en Zonas Áridas Y Semiáridas del Cono Sur de Sudamérica (P. Arenas), 251-270.

MORAIS, S. M.; DANTAS, J. D. P.; SAILVA, A. R. A.; MAGALHÃE, E. F. (2005): Plantas medicinais usadas pelos índios Tapebas do Ceará, Revista Brasileira de Farmacognosia 15 (2), 167-177.

MÜTZENBERG, D. S. (2010): Ambientes de ocupação pré-histórica no Boqueirão da Pedra Furada, Parque Nacional da Serra da Capivara-PI. Tesis, Universidade Federal de Pernambuco.

NASCIMENTO, L. R. S. L.; DE OLIVEIRA, P. E; BARRETO, A. M. F. (2009): Evidências palinológicas do processo de ocupação humana na região do Parque Nacional do Catimbau, Buíque, Pernambuco, Clio Série Arqueológica 24, 147-155.

NAVARRO, C.; CARRIÓN, J. S.; NAVARRO, J.; MUNUERA, M.; PRIETO, A. R. (2000): An experimental approach to the palynology of cave deposits, Journal of Quaternary Science 15, 603-619.

DOI: http://dx.doi.org/10.1002/1099-1417(200009)15:6<603::AIDJQS544>3.0.CO;2-F 
Aline Gonçalves de Freitas, José Sebastián Carrión García, Santiago Fernández Jiménez, Igor Pedroza, Caroline Fernandes Caromano, Leandro Mathews Cascón, Gina Faraco Bianchini, Sergio Francisco Serafim Monteiro da Silva, Neuvania Curty Ghetti, Claudia Alves de Oliveira

NIMER, E. (1989): Climatologia do Brasil. Instituto Brasileiro de Geografia e Estatística, Rio de Janeiro.

NUNES, F. P.; PORTELA, S. V. S. (2011): Plano de manejo da Reserva Particular do Patrimônio Natural - RPPN Sítio Palmeiras. Portaria DOU 141.

OLIVEIRA, A. L. N. (2001): O Sítio arqueológico Alcobaça, Buíque, Pernambuco: estudo das estruturas arqueológicas, Tesis, Universidade Federal de Pernambuco.

OLIVEIRA, C. A. (2003): Os grupos ceramistas pré-históricos do Sudeste do Piauí: estilos e técnicas, Revista da Fundação Museu do Homem Americano, São Raimundo Nonato (FUNDHAM) 1 (3), 57-127.

OLIVEIRA, C. A.; PEDROZA, I. (2014): Escavação Arqueológica do Sítio Funerário Serra do Evaristo I, Município de Baturité - Relatório Final: IPHAN, Ceará, Fortaleza.

PEARSALL, D. (1992): The Origin of Plant Cultivation in SouthAmerica, The Origin of Agriculture: an international perspective (C. W. Cowan; P. J. Watson), Washington and London, 173-205.

PEDROZA, I; OLIVEIRA, C. A.; MUTZENBERG, D.; FREITAS, A. G.; CARRIÓN, J. S. (2014): Alimentación en sierras húmedas durante la prehistoria en el nordeste de Brasil: primeros datos palinológicos del yacimiento Evaristo (Baturité, Ceará), VI Coloquio Internacional de Arqueología. Libro Resumen de la XII Conferéncia Internacional de Antropología, La Habana.

PEIXOTO JÚNIOR, R. F. (2011): Desenvolvimento e caracterização de marcadores microssatélites para Puccinia melanocephala, agente causador da ferrugem marrom em cana-de-açúcar, Master, Universidade de São Paulo.

PERRY, L. (2005): Reassessing the traditional interpretation of "manioc" artifacts in the Orinoco Valley of Venezuela, $\mathrm{La}$ tin American Antiquity 16 (4), 409-426. DOI: http://dx.doi.org/10.2307/30042507

PESSENDA, L. C. R.; SAIA, S. E. M. G.; GOUVEIA, S. E. M.; LEDRU, M. P.; SIFEDDINE, A.; AMARAL, P. G. C. (2010): Last millennium environmental changes and climate inferences in the Southeastern Atlantic Forest, Brazil, Anais da Academia Brasileira de Ciências 82, 717-729. DOI: http://dx.doi.org/10.1590/S0001-37652010000300019

PIMENTEL, C. R. M. (1988): Aspectos da distribução e produção do caju no Estado do Ceará, EMBRAPA-CNPCa. Fortaleza.

PIPERNO, D. R.; PEARSALL, D. M. (1998): The Origins of Agriculture in the Lowland Neotropics, San Diego.

PIPERNO, D. R.; ANDRES, T. C.; STOTHERT, K. E. (2000): Phytolyths in Cucurbita and other Neotropical Cucurbitaceae and their occurrence in Early Archaeological Sites from the Lowland American Tropics, Journal of Archaeological Science 27(3), 193-208.

DOI: http://dx.doi.org/10.1006/jasc.1999.0443

POMPEU SOBRINHO, T. (1955): Pré-História Cearense, Fortaleza.
PORTO ALEGRE, M. S. (2000): Evocações da terra tirada. Memória social e consciência política na tradição oral do índios Tremembé, GT Bibliografia e memória social. Universidade Federal do Ceará.

PROUS, A. (1992): Arqueologia Brasileira, Brasília.

PUNT, W.; HOEN, P. P.; BLACKMORE, S.; NILSSON, S.; THOMAS, A. (2007): Glossary of pollen and spore terminology, Review of Palaeobotany and Palynology 143, 1-81. DOI: http://dx.doi.org/10.1016/j.revpalbo.2006.06.008

QUILTER, J.; OJEDA, B.; PEARSALL, D. M.; SANDWEISS, D. H.; JONES, J. G.; WING, E. S. (1991): Subsistence economy of El Paraíso, an Early Peruvian Site, Science 251 (4991), 277-283. DOI: http://dx.doi.org/10.1126/science.251.4991.277

RIVAS-MARTÍNEZ, S. (1977): Datos sobre la vegetación nitrófila española, Acta Botanica Malacitana 3, 159-167.

ROUBIK, D. W.; MORENO, J. E. (1991): Pollen and spores of Barro Colorado Island, Monographs in Systematic Botany. Missouri Botanical Garden, Panamá 36, 270 pp. DOI:http://dx.doi.org/10.2307/4110734

RUFINO, M. U. L.; COSTA, J. T. M.; SILVA, V. A.; ANDRADE, L. H. C. (2008): Conhecimento e uso do ouricuri (Syagrus coronata) e do babaçu (Orbignya phalerata) em Buíque, PE, Brasil, Acta Botanica Brasilica 22 (4), 1141-1149. DOI: http://dx.doi.org/10.1590/s0102-33062008000400025

SABA, M. D. (2007): Morfologia polínica de Malvaceae: implicações taxonómicas e filogenéticas, Tesis. Universidade Estadual de Feira de Santana.

SALGADO-LABOURIAU, M. L. (1973): Contribuição à Palinologia dos Cerrados, Rio de Janeiro.

SANTOS, M. G.; OLIVEIRA, M. L. V. M. (2012): A territorialização dos índios Tremembé: conflitos e resistencias em Itarema-Ceará, Revista da Casa de Geografia de Sobral 14 (1), 27-43.

SCHEEL-YBERT, R. (2001): Man and vegetation in the Southeastern Brazil during the Late Holocene, Journal of Archaeological Science 28 (5), 471-480.

DOI: http://dx.doi.org/10.1006/jasc.2000.0577

SCHEEL-YBERT, R.; CAROMANO, C. F.; CASCON, L. M.; BIANCHINI, G. F.; BEAUCLAIR, M. (2010): Estudos de paleoetnobotânica, paleoambiente e paisagem na Amazônia Central e o exemplo do sudeste-sul do Brasil, Arqueologia Amazônica (E. Pereira y V. Guapindaia), Belém, 209-935.

SILVA, S. F. S. M. (2005): Arqueologia das práticas mortuárias em sítios pré-históricos no litoral de São Paulo, Tesis, Universidade de São Paulo.

SILVA, S. F. S. M.; OLIVEIRA, C.; CASTRO, V. M. C.; PEDROZA, I. (2014): Arqueologia na Serra do Evaristo, Baturité, Ceará, Brasil: resultados preliminares sobre os dados bioarqueológicos obtidos nas escavações setoriais de urnas funerárias no sítio EV1 (625 - 710 B.P). FUMDHAMentos 9, 145.

SILVA, V. A.; ANDRADE, L. H. C. (2002): Etnobotánica Xucuru: espécies místicas, Biotemas 15 (1), 45-57. 
SILVA, V.A.; ANDRADE, L.H.C. (2004): Significado cultural das espécies botânicas entre indígenas de Pernambuco: o caso Xucuru, Biotemas 17 (1), 79-94.

STUDART FILHO, C. (1962): Os Aborígenes do Ceará, Revista do Instituto Histórico do Ceará LXXVI, 5-73.

STUIVER, M.; REIMER, P. J. (1993): Extended 14C data base and revised CALIB 3.0 14C age calibration program, Radiocarbon 35, 215-230.

SUPERINTENDÊNCIA ESTADUAL DO MEIO AMBIENTE DO ESTADO DO CEARÁ (SEMACE). (1992): Zoneamento Ambiental da APA da Serra de Baturité: diagnóstico e diretrizes, Fortaleza.

VALLE, C. G. O. (2005): Torém/Toré: tradições e invenção no quadro de multiplicidade étnica do Ceará contemporáneo, Regime encantado do índio do Nordeste (R. A. Grünewald y R. A. Toré), Recife, 221-256.

VAN GEEL, B. (1981): A palaeoecological study of an Upper Late Glacial and Holocene sequence rom "De Borchert", The Netherlands, Review of Palaeobotany and Palynology 31, 367-448.

DOI: http://dx.doi.org/10.1016/0034-6667(78)90040-4
VAN GEEL, B.; GELORINI, V.; APTROOT, A.; RUCINA, S.; MARCHANT, R.; SINNINGHE DAMSTÉ, J. S.; VERSCHUREN, D. (2011): Diversity and ecology of tropical African fungal spores from a 25,000-year palaeoenvironmental record in southeastern Kenya, Review of Palaeobotany and Palynology 164, 143-173. DOI: http://dx.doi.org/10.1016/j.revpalbo.2011.01.002

VELOSO, H. P.; RANGEL FILHO, A. L. R.; LIMA, J. C. A. (1981): Classificação da vegetação brasileira adaptada a um sistema universal, Rio de Janeiro.

VIEIRA, L. J.; SOARES, T. L.; ROSSI, M. L.; ALVES, A. A. C.; SANTOS, F.A.; SOUZA, V.D. (2012): Viability, production and morphology of pollen grains for different species in the genus Manihot (Euphorbiaceae), Acta Botanica Brasilica 26 (2), 350-356.

WANG, B.; LIU, Y.-L. (2006): Phylogenetic distribution and evolution of mycorrhizas in land plants. Mycorrhiza 16, 299-363. DOI: http://dx.doi.org/10.1007/s00572-005-0033-6

WESOLOWSKI, V. (2008): Cáries, desgaste, cálculos dentários e micro-resíduos da dieta entre grupos pré-históricos do litoral norte de Santa Catarina: é possível comer amido e não ter cárie?, Revista de Arqueologia 21, 157-159. 